\title{
Pathway simulations in common oncogenic drivers of leukemic and rhabdomyosarcoma cells: A systems biology approach
}

\author{
GEORGE I. LAMBROU ${ }^{1}$, APOSTOLOS ZARAVINOS ${ }^{2}$, MARIA ADAMAKI ${ }^{1}$, DEMETRIOS A. SPANDIDOS ${ }^{2}$, \\ FOTINI TZORTZATOU-STATHOPOULOU ${ }^{1}$ and SPIROS VLACHOPOULOS ${ }^{1}$ \\ ${ }^{1}$ First Department of Pediatrics, Choremeio Research Laboratory, University of Athens, Athens 11527; \\ ${ }^{2}$ Laboratory of Virology, Medical School, University of Crete, Heraklion 71110, Crete, Greece
}

Received December 19, 2011; Accepted February 6, 2012

DOI: $10.3892 /$ ijo.2012.1361

\begin{abstract}
A part of current research has intensively been focused on the proliferation and metabolic processes governing biological systems. Since the advent of high throughput methodologies such as microarrays, the load of genomic data has increased geometrically and along with that the need for computational methods to interpret these data. In the present study, we investigated in vitro the common proliferation and metabolic processes, associated with common oncogenic pathways, as far as gene expression is concerned, between the T-cell acute lymphoblastic leukemia (CCRF-CEM) and the rhabdomyosarcoma (TE-671) cell lines. We present a computational approach, using cDNA microarrays, in order to identify commonalities between diverse biological systems. Our analysis predicted that JAK1, STAT1, PIAS2 and CDK4 are the driving forces in the two cell lines. This type of analysis may lead to the understanding of the common mechanisms that transform physiological cells to malignant, and may reveal a new holistic approach to understanding the dynamics of tumor onset as well as the mechanistics behind oncogenic drivers.
\end{abstract}

\section{Introduction}

It is a fact that tumors can be as diverse as the patients carrying them. Due to these differences, tumors are extremely difficult to cure, as the effects of treatments differ depending on the patient. Previously, Nicolis showed that stem cells are found in different tumor types, suggesting that they can be the etiology of tumor maintenance and growth (1). However, there is evidence that even normal, already differentiated cells can be transformed

Correspondence to: Dr George I. Lambrou, First Department of Pediatrics, Choremeio Research Laboratory, University of Athens, Goudi 11527, Athens, Greece

E-mail: glamprou@med.uoa.gr

Key words: T-cell acute lymphoblastic leukemia, CCRF-CEM cell line, rhabdomyosarcoma, TE-671 cell line, flow cytometry, microarrays, chromosome mapping, transcription factor binding motif analysis, Gene Ontology, pathway analysis, physical protein-protein interactions prediction into tumorigenic ones (1). Perilongo et al also reported a case of a child manifesting five different tumor types simultaneously (2). It may be possible that stem cells originating from the same organism possess similar mutations or alterations, thus giving rise to five different tumor types. Therefore, there is a need for the investigation of common pathways between different tumor types. The discovery of similar or opposite gene expression profiles could lead us to the understanding of a common tumor origin, if such exists.

A number of studies have investigated the detection of cancer germ line genes (CGGs) both in pediatric sarcomas (3) and pediatric brain tumors (4). The discovery of global antigens for tumor vaccines could become salvatory for childhood malignancies (3). Other studies have reported the common appearance of antigens in Ewing's sarcoma/primitive neuroectodermal tumor (EWS/PNET) with lymphoblastic lymphoma (5). Rhabdomyosarcoma (RMS) belongs to the PNET family of tumors, which utilize embryonic genes for their progression (6). Acute lymphoblastic leukemia (ALL), which originates from the lymphoblast, also uses embryonic mechanisms for its differentiation and progression.

Another point which requires attention is the regulation of genes through transcription factors (TFs). Knowledge of gene regulatory networks is considered to be of crucial importance for understanding diseases such as cancer, and may lead to new therapeutic approaches (7). Furthermore, the knowledge of common transcription regulatory networks could be of critical importance, as it could lead to a universal treatment for a diverse disease, such as cancer.

At the same time, there is much debate accompanying the advent of the next-generation sequencing technologies, concerning the role of mutations in the oncogenic pathways. Previous reports have stressed this issue mentioning that, on the one hand, the presence of mutations is a prerequisite for tumorigenesis, and on the other hand, some of these mutations are required for the appearance of neoplasias (8-12). In particular, in the studies by Parsons et al (13) and Pleasance et al (8) there is an effort to link the detection of mutations with gene expression in the tumor samples. At this point, we could add that the existence of one or more mutations, is probably not the adequate causative effect for the formation of a tumor, due to the fact that the existence of mutations per se, means nothing if the mechanism does not support them. 
ALL is the most frequently occurring tumor among childhood malignancies. It originates from the undifferentiated lymphoblast whose development is blocked at different stages on its way to becoming the mature lymphoid cell, thus giving rise to a tumor. Acute leukemia emerges mainly during childhood although it can also occur in adolescents, manifesting a poorer prognosis in this age group. RMS is also a rare childhood cancer comprising 5-8\% of all tumors emerging during childhood. The cell of origin is considered to be the myoblast or cells that will form the skeletal muscle. These cells differ from the smooth cells that line the intestinal tract. Theoretically, RMS can emerge in any part of the body that has skeletal muscle; however, it originates mainly in the head and neck. Thus, these two malignancies are of different origin. The common aspect between these malignancies is that they both comprise of cells that are undifferentiated, immortal and potentially divide infinitely. Also, looking back to their developmental history, both cell types originate from the embryonic mesoderm. Myoblasts originate from the dorsal (paraxial) mesoderm, whereas blood cells are derived from the lateral mesoderm which gives rise to the splanchnic mesoderm, which in turn gives rise to hemangioblastic tissue. Blood cells originate from two sites in embryogenesis: The first is considered to be the ventral mesoderm near the yolk sac, whereas hematopoietic cells that last the lifetime of an organism are derived from the mesodermal area surrounding the aorta. From this point, differentiation enables these two cell types to have different functions and roles in the body, through differential gene regulation.

Of note, it has been reported that RMS can be present in the bone marrow of patients presenting a leukemic image, without the presence of a primary tumor (14-17). It has also been reported that the presentation of a secondary malignancy after successful treatment of the primary tumor, is possible. Such a case was reported by Kaplinsky et al who showed that the successful treatment of a paravertebral embryonal RMS (ERS) resulted in the development of T-cell acute lymphoblastic leukemia (T-ALL) (18). Our query was whether the development of the secondary tumor could be the cause of cells originating from the primary tumor, due to therapyrelated leukemia, or whether it could be due to the presence of leukemic cells, which after being in a dormant state in the bone marrow, were triggered after chemotherapy of the RMS. The first case implies that the same tumor cell possesses two traits: The ability to migrate and differentiate into another cell type, thus manifesting stem cell-like properties. This reinforces the stem cell theory of the origin of cancer, as cancer stem cells keep the ability to differentiate, migrate and grow into a new malignancy, with almost completely new traits.

However, it is also known that therapy-related leukemia can occur due to the use of chemotherapeutics $(19,20)$. This phenomenon has not been thoroughly investigated and the mechanisms behind it still remain obscure. However, it points out to the fact that carcinogenesis is a complicated phenomenon, which includes a plethora of cell fate mechanisms as opposed to single events. Due to the complexity of its nature, there is currently a need for the use of computational methods in the study of carcinogenesis. Moreover, if the hypothesis of the simultaneous presence of two different tumor cells in different locations is true, this would suggest that stem cells play a major role in carcinogenesis and tumor growth. On the other hand, an interesting report by Kelly et al showed that, at least in part, the presence of cancer stem cells is not necessary for tumor growth (21).

The present study is concerned with the common expressional profile of two cell lines: The T-ALL (CCRF-CEM) and the RMS (TE-671) cell lines. Our investigation focused on the identification of genes that share a common expression profile between the two cell lines. Both cell lines are characterized by the fact that their differentiation has stopped at an early stage, before they mature to their final cell type. Normally, these cells would have matured and progressed into differentiated cells, constituting blood and muscle cells, respectively. At some unknown point, normal differentiation ceased for these cells and they became malignant. From that point on, to the first manifestation of symptoms of malignancy, there is a lack of knowledge regarding the mechanisms underlying oncogenesis.

From these observations, the question arises of whether two distinct cell types destined to fulfill different functions, manifest similar mechanisms of growth and progression due to their malignant character. The present study focused on the identification of the differential expression profiles underlying the two cell lines. A previous report studied the expression profile of seven ARMS cell lines possessing the PAX3-FKHR fusion gene, along with other cell lines of different tumor types (22). To our knowledge, this is the first report comparing two completely different types of neoplasia, such as the CCRF-CEM and TE-671 cell lines. These mechanisms are examined with the purpose of identifying common drivers that lead to the progression of tumor cells. We hereby propose a new computational approach for the investigation of common oncogenic drivers.

\section{Materials and methods}

Cell cultures. The CCRF-CEM (ALL) and the TE-671 (RMS) cell lines were used as the model, both obtained from the European Collection of Cell Cultures (ECACC). The CCRF-CEM cell line, a CD4 ${ }^{+}(23)$ and $\mathrm{CD} 34^{+}$presenting cell line (24), was initially obtained from the peripheral blood of a two-year-old Caucasian female. The tumor was diagnosed as lymphosarcoma which later progressed to acute leukemia (25). The child had undergone irradiation therapy and chemotherapy prior to obtaining the cell line. Although remission was achieved at various stages, the disease progressed rapidly (25). The cell line has been observed to undergo minor changes after long-term culture, except for the presence of dense granules in the nucleoli (26). Finally, the CCRF-CEM cell line has been reported to manifest autocrine catalase activity which participates in its mechanisms of growth and progression (27).

The TE-671 cell line was initially reported to have been obtained from a cerebellar medulloblastoma of a six-year old Caucasian female, prior to irradiation therapy (28), and characterized later on (29). However, it is currently known that this cell line is parental if not identical to the RD (30) RMS cell line. However, a number of reports still refer to this cell line as medulloblastoma $(31,32)$.

Both cell lines were seeded at the $-24 \mathrm{~h}$ time-point and allowed to grow overnight. After $24 \mathrm{~h}$ (time, $0 \mathrm{~h}$ ) a sample was taken from both cell lines in order to perform measurements 
and every $24 \mathrm{~h}$ thereafter. CCRF-CEM cells were grown in RPMI-1640 medium supplemented with $2 \mathrm{mM}$ L-glutamine and $100 \mathrm{U} / \mathrm{ml}$ streptomycin/penicillin (Gibco), 20\% FBS (Gibco) at $37^{\circ} \mathrm{C}, 5 \% \mathrm{CO}_{2}$ and $\sim 100 \%$ humidity. TE-671 cells were grown in DMEM (Gibco) medium supplemented with $2 \mathrm{mM}$ L-glutamine, 10\% FBS and $100 \mathrm{U} / \mathrm{ml}$ streptomycin/ penicillin. Cells were allowed to grow to $\sim 1.500 \times 10^{3}$ cells $/ \mu$ l for CCRF-CEM and at $\sim 80 \%$ confluence for TE-671. Cells were harvested at confluence using $0.1 \%$ trypsin (only for TE-671) and centrifugation at $1000 \mathrm{rpm}$ for $10 \mathrm{~min}$. The supernatant was discarded and the cells were washed with pre-warmed $1 \mathrm{X}$ PBS, re-centrifuged at $1000 \mathrm{rpm}$ for $10 \mathrm{~min}$ and the pellet was kept for further processing.

Cell proliferation. Cell population counts were determined with the use of a Nihon Kohden CellTaq- $\alpha$ hematology analyzer. Cells were counted at the -24-h time-point as well as at 0, 4, 24, 48 and $72 \mathrm{~h}$ after being allowed to grow under normal conditions. For this purpose, $200 \mu \mathrm{l}$ of cell suspensions were obtained from each flask and counted directly with the analyzer.

Flow cytometry. Flow cytometry was performed on a FlowCount XL flow cytometer (Beckman Coulter, Brea, CA, USA). Cell cycle distribution and DNA content was determined with standard PI staining (Invitrogen Inc., Grand Island, NY, USA). Briefly, $1 \mathrm{ml}$ of cell suspension from each flask was centrifuged at $1000 \mathrm{rpm}$ for $10 \mathrm{~min}$. The supernatant was removed and cells were suspended in $1 \mathrm{ml} \mathrm{75 \%}$ ethyl alcohol. The cells were incubated at $4^{\circ} \mathrm{C}$ overnight. After incubation, cells were centrifuged at $1000 \mathrm{rpm}$ for $10 \mathrm{~min}$. The supernatant was removed and cells were washed with $1 \mathrm{ml}$ ice-cold PBS, $\mathrm{pH}$ 7.4. Cells were re-centrifuged and re-diluted in $1 \mathrm{ml}$ PBS pH 7.4. RNase A $(0.25 \mu \mathrm{g} / \mathrm{ml})$ was added and cells were incubated at $37^{\circ} \mathrm{C}$ for $30 \mathrm{~min}$ in order to remove any remaining traces of RNA that could interfere with PI staining. PI was added to a final concentration of $1 \mu \mathrm{g} / \mathrm{ml}$. All experiments were performed in triplicate. The reported data constitute the average of three independent experiments.

Flow cytometry data analysis. Flow cytometry and cell cycle data were analyzed with WinMDI software version 2.8 (The Scripps Research Institute, Flow Cytometry Core Facility) and Cylchred version 1.0.2 (Cardiff University, Wales) which is based on the algorithms proposed by Ormerod et al and Watson et al (33-35).

RNA isolation. RNA was isolated with TRIzol reagent (Invitrogen Inc.) according to the manufacturer's instructions. The amount of RNA isolated was measured with a SmartSpec 3000 spectrophotometer (BioRad, Berkley, CA, USA) and RNA integrity was estimated by $2 \%$ agarose gel electrophoresis. At least $40 \mu \mathrm{g}$ of RNA from each sample was used. DNase treatment (RQ1 DNAse; Promega, Fitchburg, WI, USA) followed, as described by the manufacturer. Finally, RNA samples were further purified using the RNeasy mini kit (Qiagen, Hilden, Germany) and RNA amounts and integrity were determined again as above. Samples with a 1.8 to $2.0 \mathrm{~A}_{260} / \mathrm{A}_{280}$ ratio were selected. In addition, those that empirically showed a twice as bright $28 \mathrm{~S}$ band compared to the $18 \mathrm{~S}$ band on the gel were utilized.
Microarray experimentation. For the assay of mRNA levels two sets of microarray chips were used: cDNA microarray chips (4.8 k genes) obtained from Takara (IntelliGene ${ }^{\mathrm{TM}}$ II Human CHIP 1) (36) and microarray chips (9.6 k genes) from the Institute for Molecular Biology and Tumor Research, Microarray Core Facility of the Philipps University, Marburg, Germany (IMT9.6 k). Hybridization was performed with the CyScribe Post-Labeling kit [GE Healthcare (former Amersham Inc.), Buckinghamshire, UK] as described by the manufacturer. The fluorescent dyes used were $\mathrm{Cy} 3$ and $\mathrm{Cy} 5$. The RNA extracted from the CCRF-CEM cells was stained with Cy3 (reference) and RNA from the TE-671 cell line with Cy5 (experiment). cDNAs were purified with Qiagen PCR product clean-up kit. Slides were activated at $55^{\circ} \mathrm{C}$ for $30 \mathrm{~min}$ in $1 \%$ BSA. Samples were applied on the slides, and allowed to hybridize overnight at $55^{\circ} \mathrm{C}$. The following day, slides were washed in $200 \mathrm{ml} 0.1 \mathrm{X} \mathrm{SSC}$ and $0.1 \%$ SDS for $3 \times 5 \mathrm{~min}$, in

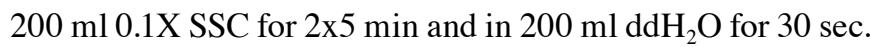
Slides were dried by centrifugation at $1500 \mathrm{rpm}$ for $3 \mathrm{~min}$ and scanned with a ScanArray 4000XL microarray scanner [Perkin-Elmer Inc. (former GSI Lumonics), Waltham, MA, USA]. Images were generated with ScanArray microarray acquisition software (Perkin-Elmer Inc.). The microarray data have been submitted to the GEO Database (Accession No. GSE34522).

\section{Microarray data analysis}

Data collection. Microarray data pre-processing analysis was performed with ImaGene ${ }^{\circledR}$ v.6.0 Software (BioDiscovery Inc., El Segundo, CA, USA) and Armada software (National Hellenic Research Foundation, Athens, Greece) (37). Data were collected from exported text file and data pre-processing was performed using Microsoft Excel ${ }^{\circledR}$. Data were processed in two ways: The first included the separation of each channel (Cy3 and Cy5), and the second included pre-processing of the ratio between the two samples.

Data pre-processing and background correction. A common pre-processing stage was applied to the raw data (the median intensity value in each channel) of both platforms. Specifically, the well performing version of the robust loessbased background correction (rLsBC) approach, as proposed by Sifakis et al was applied (38). rLsBC assumes that the background noise affects the spot intensities in a multiplicative manner (39). Instead of using the measurements of the local (feature-related) background for the correction, rLsBC utilizes the regression estimate of the logarithmic background distribution $B^{R, G}$ according to the logarithmic foreground intensity $F^{R, G}$ for each channel (R, red and $\mathrm{G}$, green). Thus, rLsBC provides a robust estimation of the channel-specific background noise, utilized to background-correct the logarithmic foreground intensities: $F_{c}^{R, G}=F^{R, G}-B_{l}^{R, G}$ where $F_{c}^{R, G}$ is the logarithmic background-corrected foreground intensity, and $B_{l}^{R, G}$ the robust estimate of background noise, for each channel. The absolute background-corrected foreground intensity $f_{c}^{R, G}$ for each channel was then calculated as: $f_{c}^{R, G}=2 F_{c}^{R, G}$

Normalization. The background-corrected signal intensities were further normalized in order to mitigate the effect of extraneous, non-biological variation in the measured gene expression levels. Normalization was performed by using six different methods: i) No further processing after background correction, 
ii) $\log _{2}$ transformation, iii) lowess normalization, iv) division with the global median (median of the $50 \%$ percentile), v) subtraction of global median (the median of the $50 \%$ percentile) and vi) rank invariant with running median. Finally, the rank invariant normalization method was chosen for further processing and analysis (40-42). The rank invariant normalization approach included the robust version of the intensity-dependent scatterplot smoother loess (43) with a quadratic polynomial model, and a smoothing parameter equal to $10 \%$, which was considered appropriate for the relatively small number of probes attached in the microarrays. The normalization results are presented in Fig. 1. Box plots were used to examine normalization efficiency as presented in Fig. 1D.

Data integration. We performed data integration at a lower level as previously described (44). Specifically, the pre-processed datasets of each array were combined into one unified dataset, in which standard statistical procedures were applied. Nonetheless, whenever applicable to the nature of the present study, certain key issues had to be addressed, such as pre-processing, preparation and annotation of the individual datasets, in compliance with previously reported guidelines (45). In order to perform data integration, two main issues had to be resolved: i) Matching reporters on the two microarray platforms, and ii) normalizing data to address platform-related differences (46). Specifically, each reporter-level identifier (GenBank accession numbers) was mapped to a UniGene identifier (UniGene Cluster ID) (47-51). The mapping was performed through the Source web-based tool (52), simultaneously for both platforms, in order to avoid inconsistencies (53). All mapped reporter-level identifiers had a one-to-one relationship with the gene-level identifiers, that is, each reporter was associated with a single UniGene identifier and no more than one reporter was mapped to the same UniGene identifier. Reporters having insufficient information to be mapped to any gene-level identifier were omitted. Thus, a fully updated set of unique gene-level identifiers was generated for each platform.

Filtering. As low signal intensity measurements are less reliable in terms of the impact of noise on them than high gene expression measurements, an intensity-dependent filtering $(54,55)$ with an absolute threshold value of 10 was used in each channel, in order to exclude low quality features. In addition, signal-to-noise ratio was used as:

$$
S N R=\frac{\mu_{R, G}-\mu_{B}}{\sigma_{B}}
$$

where $\mu_{R, G}$ and $\mu_{B}$ is the mean value intensity for the respective channel (Cy3 or Cy5) and mean background intensity, respectively; and $\sigma_{B}$ is the background mean signal standard deviation. A threshold of 2 was set as a cut-off value, meaning that spot intensity for at least one channel should be twice as much as that of the background.

Analysis. The data were further analyzed in order to identify the differentially expressed genes (DEGs) and the groups of genes that share common expression characteristics. Analysis steps were conducted in the Matlab ${ }^{\circledR}$ computing environment.

Identification of DEGs. Furthermore, each gene was tested for its significance in differential expression using a z-test. Genes were considered to be significantly differentially expressed if they obtained a p-value $<0.05$. The false discovery rate (FDR) was calculated as previously described (56-58). There was a FDR of $1 \%$ for $\mathrm{p}<0.05$ for the IntelliGene microarray chip, and a FDR of $9 \%$ for $\mathrm{p}<0.01$ for the IMT $9.6 \mathrm{k}$ microarray chip. Calculating the FDR for the combination of both platforms gives a FDR of $6 \%$ for $\mathrm{p}<0.01$. The DEGs per experiment were identified at a confidence level of $95 \%$.

Chromosome mapping. Chromosome mapping was performed with Genesis 1.7.2 software (Technische Universitaet-Graz, Austria) using Pearson's correlation, Spearman's rank order correlation (59-61) and the WebGestalt web-tool (Vanderbilt University, The Netherlands; http://bioinfo.vanderbilt.edu/ gotm/) (62).

Transcription factor binding motif (TFBMs) analysis. TFBMs were searched in the Transcription Element Listening System Database (TELiS) (www.telis.ucla.edu) (63) and WebGestalt web-tool (Vanderbilt University; http://bioinfo.vanderbilt.edu/ gotm/) (62). The TRANSFAC TF database was used for the identification of gene TF binding sites (64).

Gene Ontology (GO) analysis. GO analysis was performed using the eGOn online tool for Gene Ontology (The Norwegian University of Science and Technology, Trondheim, Norway, http://www.genetools.microarray.ntnu.no/egon/) (65), Genesis 1.7.2 software (60) and the WebGestalt web-tool (62). Correlations between the DEGs and the TFBMs were further investigated using the PubGene Ontology Database (www. pubgene.org). For literature search the Microarray Literaturebased Annotation (MILANO) (http://milano.md.huji.ac.il/; Department of Molecular Biology, Hadassah Medical School, Hebrew University, Jerusalem, Israel) web-based tool was utilized (66). Gene definitions and functions were based on the National Institutes of Health databases (http://www.ncbi.nlm. nih.gov/sites/entrez/).

Pathway analysis. The DEGs were mapped on different pathways using Pathway Explorer software (Technical University of Graz, Austria) (67). The percentage of genes that were present in all known pathways was investigated, using the databases available through the Pathway Explorer software. The KEGG database of pathways was used for our analysis (68-72), as well as CellDesigner $(73,74)$ and Matlab v.7.6.0 computation environment with SimBiology ${ }^{\circledR}$. For the analysis of merged pathways the KEGGConverter Tool was utilized (National Hellenic Research Foundation, Athens Greece, http://www.grissom.gr/keggconverter) (75).

\section{Results}

Cell proliferation, morphology and cell cycle. Cells were allowed to grow under normal conditions for a total of $96 \mathrm{~h}$ (from -24 to $72 \mathrm{~h}$ ) until they reached a final population of $\sim 1.5 \times 10^{3}$ cells $/ \mu$ l. Cells were harvested and processed further for cell cycle distribution. As expected, cells manifested different forward vs. side scatter (FS vs. SS) distributions (Fig. 2C and D). CCRF-CEM cells manifested a more homogeneous population compared to TE-671 cells. TE-671 cells 


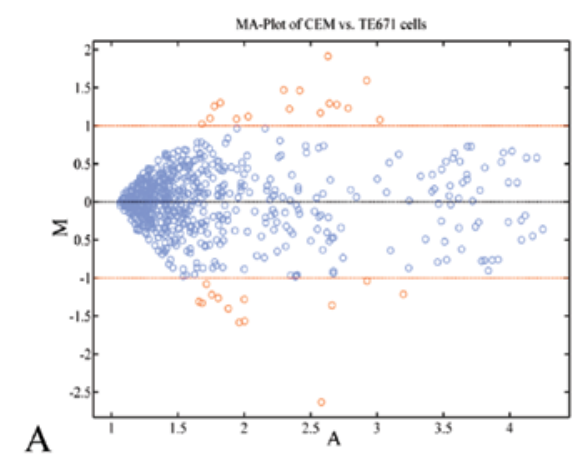

M-A plots Rank Invariant Normalization ofCy3 Channel
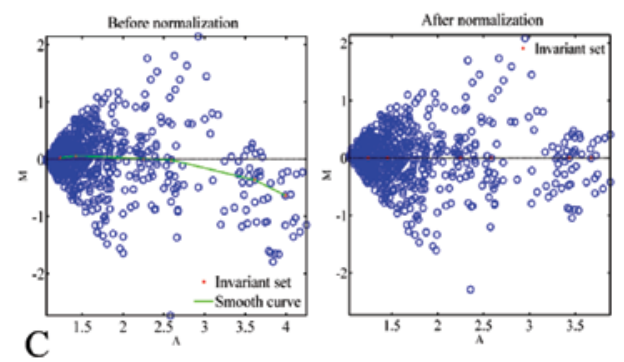

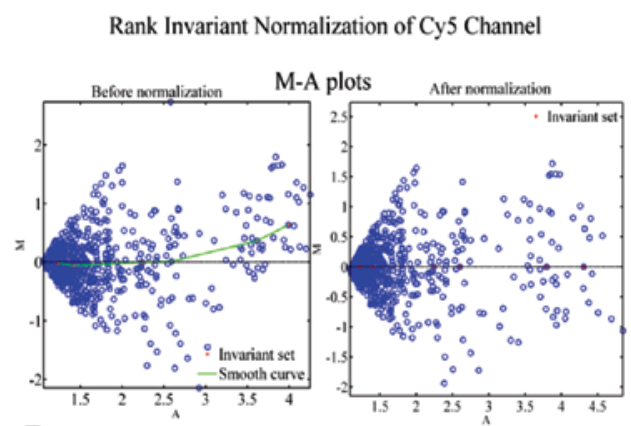

B

$\mathrm{D}$

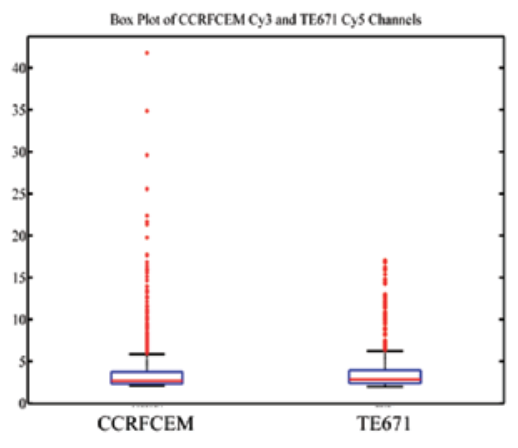

Figure 1. Microarray data normalization. (A) MA plot with robust loess normalization. Rank invariant normalization for the (B) Cy5 and (C) Cy3 channels. (D) A box-plot of the two channels manifests that normalization has eliminated the bias between the two samples.
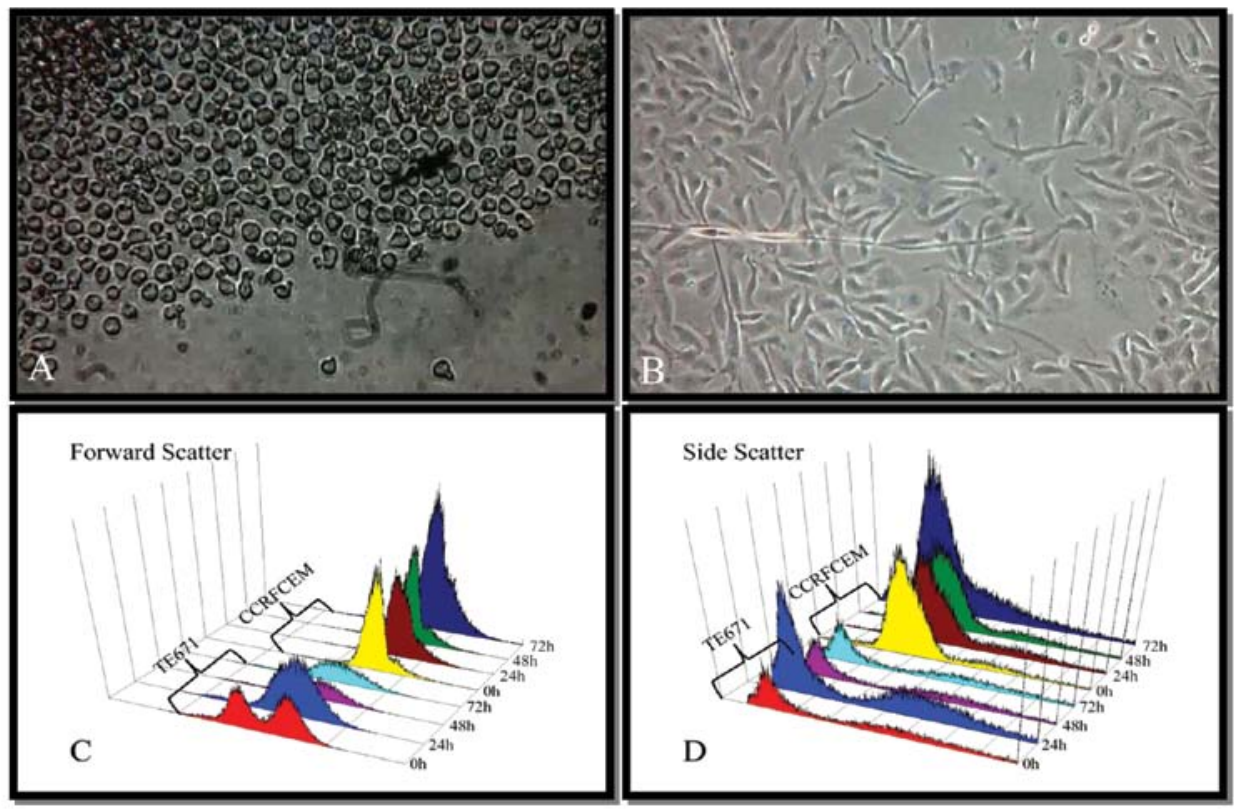

Figure 2. Morphology of the (A) CCRF-CEM and (B) TE-671 cell lines as presented by microscopy. Flow cytometry using the (C) forward scatter plot and (D) side scatter plot.

manifested a cell population with greater variance both for size and granularity. This was expected since CCRF-CEM cells grow in suspension (Fig. 2A) which gives more uniformity to their morphology, whereas TE-671 cells are adherent (Fig. 2B) and when trypsinized, they produce a cell population with a different morphology. Cell cycle distribution showed a different pattern of growth. CCRF-CEM cells entered the
S-phase rapidly after $24 \mathrm{~h}$ in culture (from -24 to $0 \mathrm{~h}$ ) and displayed cycling behavior thereafter (Fig. 3A). This indicated that the cell cycle for this type of cell is rapid, since the interchange between the phases progressed rapidly. The TE-671 cells entered the S-phase with a slower decrease in G1-phase changes and a relatively small change in G2-phase (Fig. 3B). No significant differences were observed in the G2-phase 


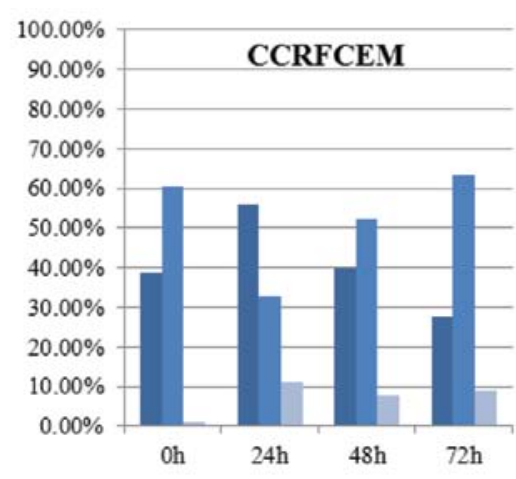

CCRFCEM Apoptosis

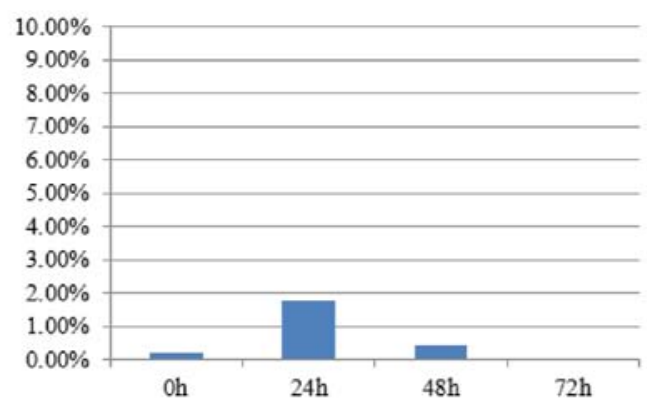

A

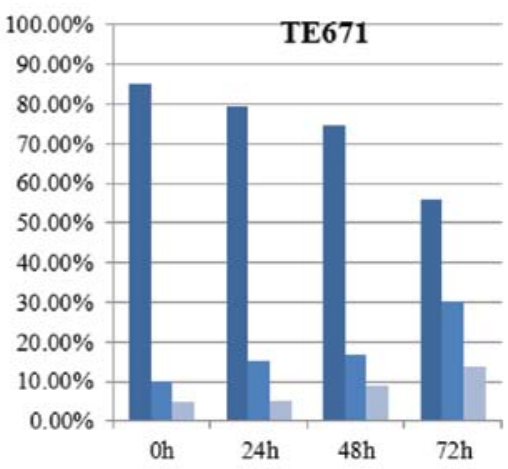

B

$=\mathrm{G} 1 / \mathrm{G} 0$

$=\mathrm{S}$

$=\mathrm{G} 2 \mathrm{M}$
TE671 Apoptosis

C

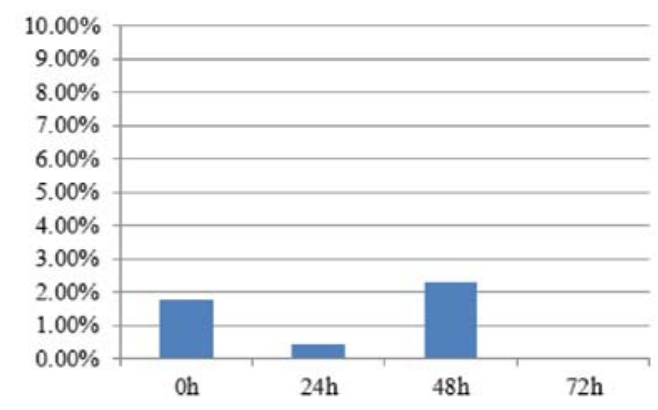

Figure 3. Cell cycle distribution with respect to time for the (A) CCRF-CEM and (B) TE-671 cell lines. Apoptosis was very low for the (C) CCRF-CEM and (D) TE671 cell lines.

between the two cell lines. Although both cell lines enter the cell cycle phases in different percentages, they follow the same growth pattern, indicating a common pattern of reaction to environmental stimuli, in this case spatial-temporal growth. This growth pattern was expected to be reflected on the gene expression profile at $72 \mathrm{~h}$. In addition, apoptosis measured as the fraction of cells with DNA fragmentation for the CCRF-CEM (Fig. 3C) and the TE671 cells (Fig. 3D) showed very low levels indicating that cells were proliferating under ideal conditions.

Microarrays. At $72 \mathrm{~h}$ the cells were harvested and further processed for microarray analysis. As mentioned in Materials and methods we analyzed our data in two ways: First, we separated the two channels and compared the intensities of each gene within the same cell type; and second, we considered the ratio of the two samples and analyzed them, respectively. DEGs were identified using the z-test, and genes with a p-value $<0.05$ were considered significant. All other genes were considered to be equally expressed. Microarray analysis of the Takara and IMT platforms showed a total of 660 and 45 genes, respectively (including ESTs) i.e., good quality spots showing the three main types of expression (over-, under- and unchanged expression). In total, from the revealed genes, 228 are reported to be related to leukemia, 78 to RMS, 76 to the CCRF-CEM cell line and eight to the TE-671 cell line. Fig. 4 presents the DEGs acquired by each type of analysis. The significantly expressed genes in both samples, as well as in the comparison between them, were AF143888, AK025762, BTBD3, CYP39A1, KCTD3, NM_016130, NPFF and UBFD1. All these genes were downregulated in the TE-671 cells, compared to the CCRF-CEM cells (Fig. 4C). These genes are possibly the ones that are unique to each cell type and are what differentiates the two cell types from each other. In Table I we summarize the list of the DEGs.

Chromosome mapping. Genes were mapped on the 24 human chromosomes. Chromosome mappings included: i) All genes after filtering for each channel separately, ii) ratio of samples for all genes after filtering, iii) common DEGs for each channel separately, iv) DEGs for the ratio of samples, v) common nonsignificant genes for each channel separately and to the ratio of samples.

All genes after filtering for each channel separately. There was a relatively equivalent distribution of DEGs on each chromosome, with an exception of chromosome 1, on which 71 genes $(10.66 \%)$ were mapped. Chromosome 2 contained 48 DEGs (7.21\%), followed by chromosome 6 with 36 DEGs (5.4\%), and chromosomes 4 and 10 with 31 and 25 DEGs, respectively $(\sim 4.7 \%)$. On chromosomes $3,5,11,12,15$ and 19 $\sim 25$ DEGs ( 4\%) were mapped. The $\mathrm{X}$ chromosome contained 31 DEGs (3.7\%) (Fig. 5). One interesting observation was that the number of genes did not correlate with the levels of expression on each chromosome. Thus, the highest levels of expression were observed on chromosomes 12,18 and 19 and not on chromosomes 1 and 2, which had the largest number of genes mapped.

Ratio of samples for all genes after filtering. The mean gene expression was estimated for the ratios of $\mathrm{Cy} 5$ over $\mathrm{Cy} 3$ (Fig. 6). The highest average expression was noticed on chromosome 14.

Common DEGs for each channel separately. The separation of the DEGs based on their chromosomal expression is 
Table I. Significantly expressed genes in each channel (Cy3 and Cy5) as well as within the ratio TE-671/CCRF-CEM.

\begin{tabular}{|c|c|c|c|c|c|c|c|}
\hline Gene & CCRF-CEM_Cy3_pval & Intensity & Gene & TE-671_Cy5_pval & Intensity & Gene & CCRF-CEM vs. TE-671 \\
\hline CYP39A1 & $7.1181 \mathrm{E}-18$ & 41.78389 & IL2RA & $1.1722 \mathrm{E}-06$ & 19.8 & AF143888 & -1.11181989 \\
\hline NPFF & $2.06086 \mathrm{E}-12$ & 34.88156 & FEM1B & $1.87947 \mathrm{E}-06$ & 16.05107 & AK025762 & -1.060984567 \\
\hline TIMP4 & $2.06086 \mathrm{E}-12$ & 34.88156 & ZZEF1 & $5.12501 \mathrm{E}-06$ & 13.49114 & AP1M2 & -2.18484153 \\
\hline UBFD1 & $5.71072 \mathrm{E}-09$ & 29.62511 & NT5C2 & $8.51751 \mathrm{E}-06$ & 9.22704 & ARNTL & 1.091262573 \\
\hline AF143888 & $1.00031 \mathrm{E}-06$ & 25.55424 & FBXL3 & $1.01757 \mathrm{E}-05$ & 8.089721 & BTBD3 & -1.142440024 \\
\hline AP1M2 & $3.21699 \mathrm{E}-05$ & 22.35297 & PDCD5 & $2.16887 \mathrm{E}-05$ & 8.873451 & $\mathrm{C} 2$ & -1.290484292 \\
\hline DLC1 & $3.21699 \mathrm{E}-05$ & 22.35297 & YARS & 5.35643E-05 & 16.05107 & CCDC53 & -1.038802341 \\
\hline ZHX3 & $3.21699 \mathrm{E}-05$ & 22.35297 & HTR2B & 5.92953E-05 & 8.480922 & CEP110 & 1.025893175 \\
\hline BTBD3 & $3.21699 \mathrm{E}-05$ & 22.35297 & AF143323 & 5.92953E-05 & 17.7375 & CSNK2A2 & -2.139800134 \\
\hline AK025762 & $6.28664 \mathrm{E}-05$ & 21.67371 & SETD4 & $9.67539 \mathrm{E}-05$ & 8.394905 & CTGF & -1.089390928 \\
\hline KCTD3 & $8.58147 \mathrm{E}-05$ & 21.34997 & LOC151146 & 0.00012813 & 13.49114 & CXCL11 & 1.016058683 \\
\hline FNDC5 & 0.000354065 & 19.8 & ZHX3 & 0.00073264 & 22.35297 & CYP39A1 & -1.707316518 \\
\hline FAM149B1 & 0.000354065 & 19.8 & CYP39A1 & 0.000985502 & 41.78389 & DACH1 & -1.24508579 \\
\hline IL2RA & 0.000354065 & 19.8 & TEAD3 & 0.00101255 & 10.69104 & FRMD4A & -2.206263944 \\
\hline NM_016130 & 0.000354065 & 19.8 & FNDC5 & 0.001045795 & 19.8 & GCHFR & 1.126350953 \\
\hline CSNK2A2 & 0.001940284 & 17.7375 & ELF2 & 0.00113142 & 10.3248 & GRB10 & 1.301414043 \\
\hline AF143323 & 0.001940284 & 17.7375 & NPFF & 0.001395187 & 34.88156 & HCCS & 1.225409758 \\
\hline AF339813 & 0.001940284 & 17.7375 & WDR73 & 0.001994343 & 9.299133 & HPS5 & 1.375196388 \\
\hline REG1B & 0.00206522 & 17.65667 & DLC1 & 0.002682338 & 22.35297 & IQSEC3 & 1.607186666 \\
\hline WNT5A & 0.003774239 & 16.85313 & UBFD1 & 0.002682338 & 29.62511 & KCTD3 & -1.176427672 \\
\hline C2 & 0.00518102 & 16.41317 & ST8SIA5 & 0.002798241 & 13.96587 & KIAA1576 & -1.423011109 \\
\hline CАMKК2 & 0.006677182 & 16.05107 & AK023784 & 0.003175562 & 8.229248 & MAPK10 & 1.42649399 \\
\hline FEM1B & 0.006677182 & 16.05107 & AF143888 & 0.003312011 & 25.55424 & NM_016130 & -1.053562688 \\
\hline FRMD4A & 0.006677182 & 16.05107 & CXorf1 & 0.003352045 & 12.71281 & NM_033330 & -1.681687739 \\
\hline YARS & 0.006677182 & 16.05107 & CDKN2AIP & 0.003836985 & 7.582367 & NPFF & -1.47748396 \\
\hline PRC1 & 0.007626474 & 15.85763 & AF339813 & 0.004262618 & 17.7375 & NTRK3 & -1.630961081 \\
\hline HEATR5A & 0.009286442 & 15.56609 & IFNG & 0.00474939 & 10.94917 & PIP4K2A & 1.139230626 \\
\hline DACH1 & 0.012670831 & 15.09318 & ZFP112 & 0.005613631 & 9.07462 & PNPLA4 & 1.308630477 \\
\hline SPRED2 & 0.016721875 & 14.65653 & RAB1A & 0.005782065 & 2.301637 & PTEN & -1.875701466 \\
\hline ST8SIA5 & 0.025456793 & 13.96587 & CAMKK2 & 0.009469924 & 16.05107 & RAB11A & -1.108030918 \\
\hline PLEKHG1 & 0.026325184 & 13.90909 & PLEKHG1 & 0.010509901 & 13.90909 & RAB1A & 2.300999087 \\
\hline LOC151146 & 0.033541148 & 13.49114 & PHACTR1 & 0.010548857 & 10.13494 & RLF & -1.183184819 \\
\hline ZZEF1 & 0.033541148 & 13.49114 & ZDHHC13 & 0.010906781 & 8.082386 & SHBG & -1.399176198 \\
\hline NM_001174 & 0.038312596 & 13.25541 & WNT5A & 0.011061282 & 16.85313 & SPCS2 & 1.242593156 \\
\hline WDR82 & 0.038379272 & 13.2523 & WDR35 & 0.011685815 & 6.237717 & TIMP4 & -3.215464573 \\
\hline \multirow[t]{16}{*}{ NM_033330 } & 0.039661634 & 13.19332 & PRC1 & 0.012011647 & 15.85763 & TNFAIP3 & -1.129228828 \\
\hline & & & ADORA1 & 0.012201291 & 12.50751 & TPD52L2 & 1.537979298 \\
\hline & & & ARHGEF7 & 0.015813135 & 7.076865 & UBFD1 & -1.303757805 \\
\hline & & & AK025762 & 0.016007345 & 21.67371 & WSB2 & 1.046956075 \\
\hline & & & NM_001174 & 0.016007345 & 13.25541 & ZNF184 & -1.133300923 \\
\hline & & & NAV3 & 0.017381377 & 11.20593 & & \\
\hline & & & SPRED2 & 0.020097086 & 14.65653 & & \\
\hline & & & BTBD3 & 0.020771574 & 22.35297 & & \\
\hline & & & FAM149B1 & 0.024638426 & 19.8 & & \\
\hline & & & C15orf23 & 0.027589911 & 11.52492 & & \\
\hline & & & IKZF5 & 0.027751518 & 12.07221 & & \\
\hline & & & NM_016130 & 0.036060401 & 19.8 & & \\
\hline & & & HEATR5A & 0.03756187 & 15.56609 & & \\
\hline & & & KCTD3 & 0.039205175 & 21.34997 & & \\
\hline & & & REG1B & 0.040634735 & 17.65667 & & \\
\hline & & & WDR82 & 0.040927424 & 13.2523 & & \\
\hline
\end{tabular}




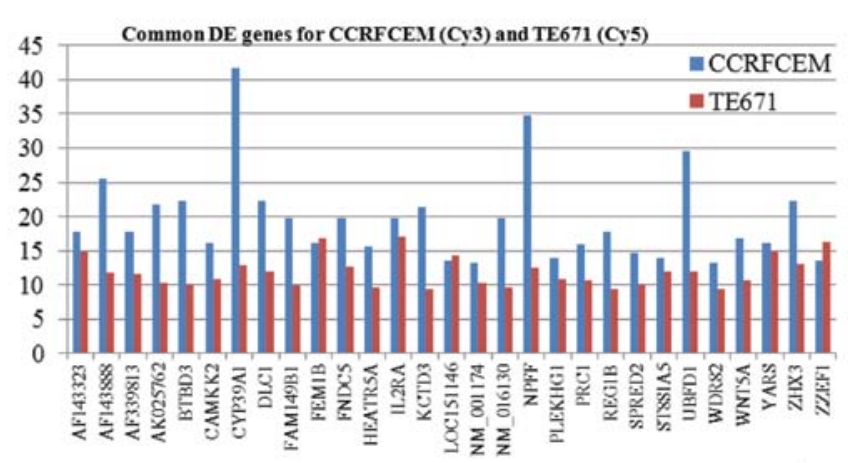

A
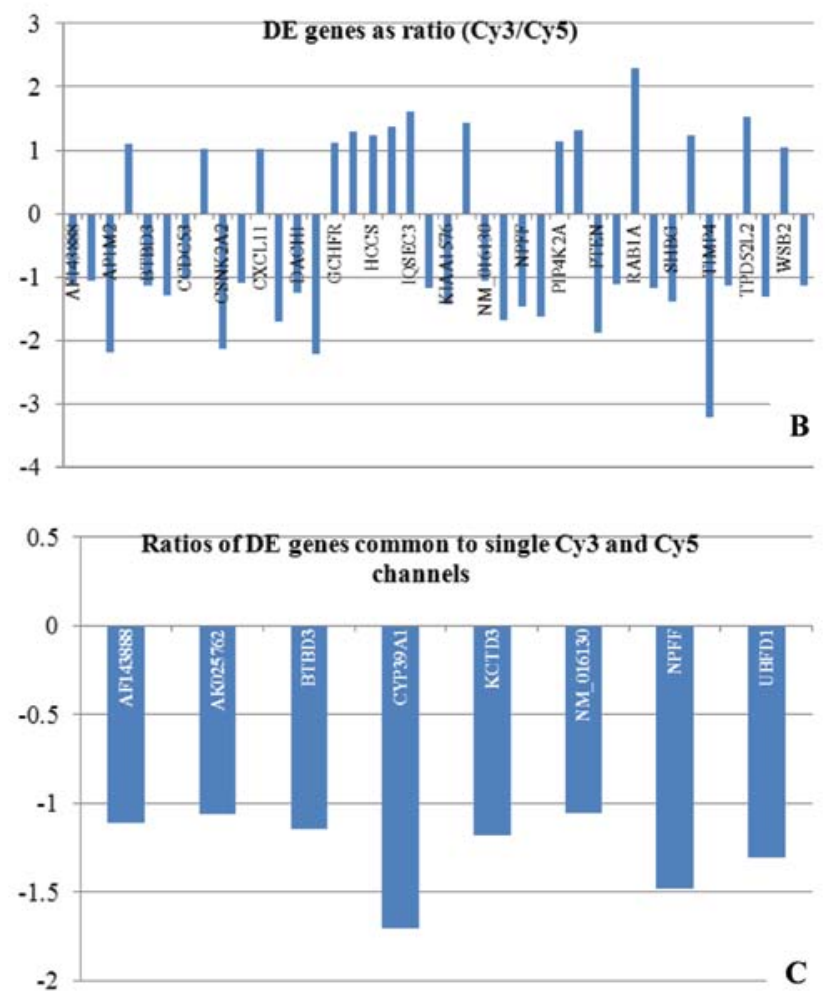

Figure 4. Microarray data of (A) each channel, (B) of gene ratios and (C) common DEGs both to individual channels and ratios. DE, differentially expessed.

presented in Fig. 7. Highest levels of expression were observed on chromosomes 6 and 16.

DEGs for the ratio of samples. The DEGs were also explored with respect to the ratio between the two samples (Fig. 8).

Common non-significant genes for each channel separately and to the ratio of samples. Finally, we explored the chromosomal distribution of the common non-significant genes, since they are commonly expressed in both cells. The results are presented in Fig. 9.

Correlation between gene numbers and gene expression. Our observation after analyzing the chromosome-based intensities was that the gene number per chromosome was irrelevant to the gene expression levels. This led us to the assumption that there may be a correlation pattern between chromosomes, genes and expression levels. Therefore, we attempted to perform fitting and simulation procedures in our data, in order to find such patterns. Curve fittings did not give significant
Chromosomal Distribution of Dataset
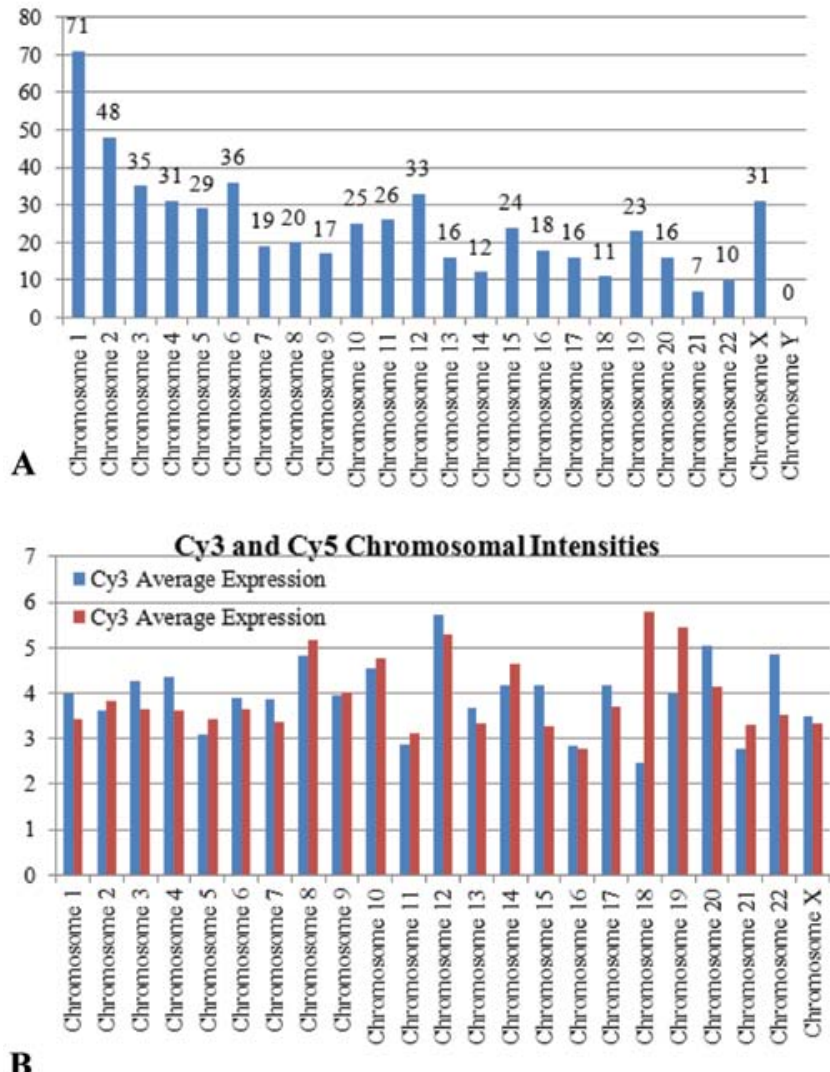

Figure 5. (A) Chromosomal expression of all genes, and (B) separately for each channel (Cy3 and Cy5).

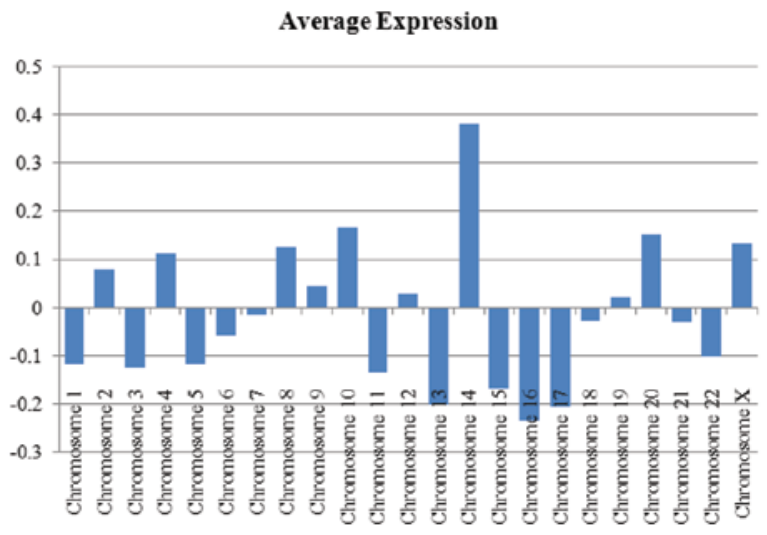

Figure 6. Chromosome-based average gene expression of the ratio Cy5/Cy3 .

results (Fig. 10A-D). A possible reason for this is that chromosome expression on the one hand should follow some basic dynamics rules, but on the other hand it is of non-linear nature; therefore, it cannot be fitted with linear equations. Continuing with this analysis, 3D surface fittings produced some interesting results, as it appeared that the average gene expression either as single intensities or ratios, was fitted with polynomial and loess approximations with a $\mathrm{R}^{2}>0.9$ and root mean square error (RMSE) of $<0.4$ (Fig. 10E-H). 


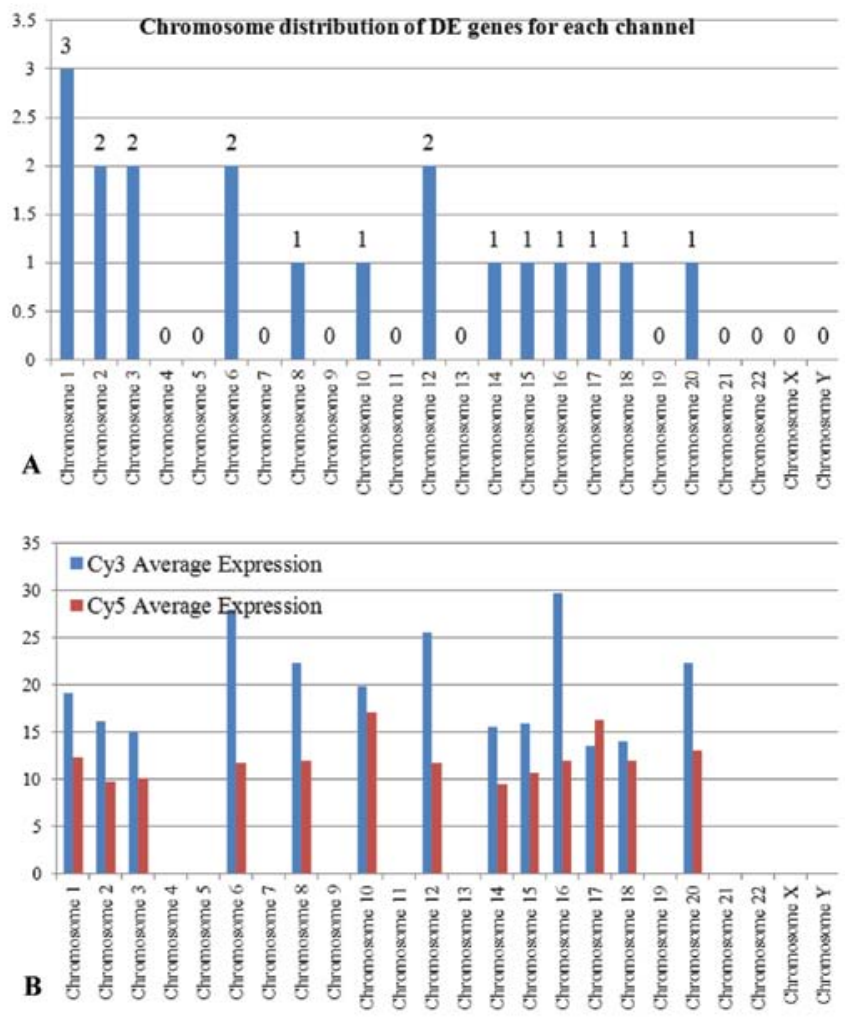

Figure 7. (A) Chromosome distribution and (B) expression of the DEGs, separately for each channel (Cy3 and Cy5). DE, differentially expessed.
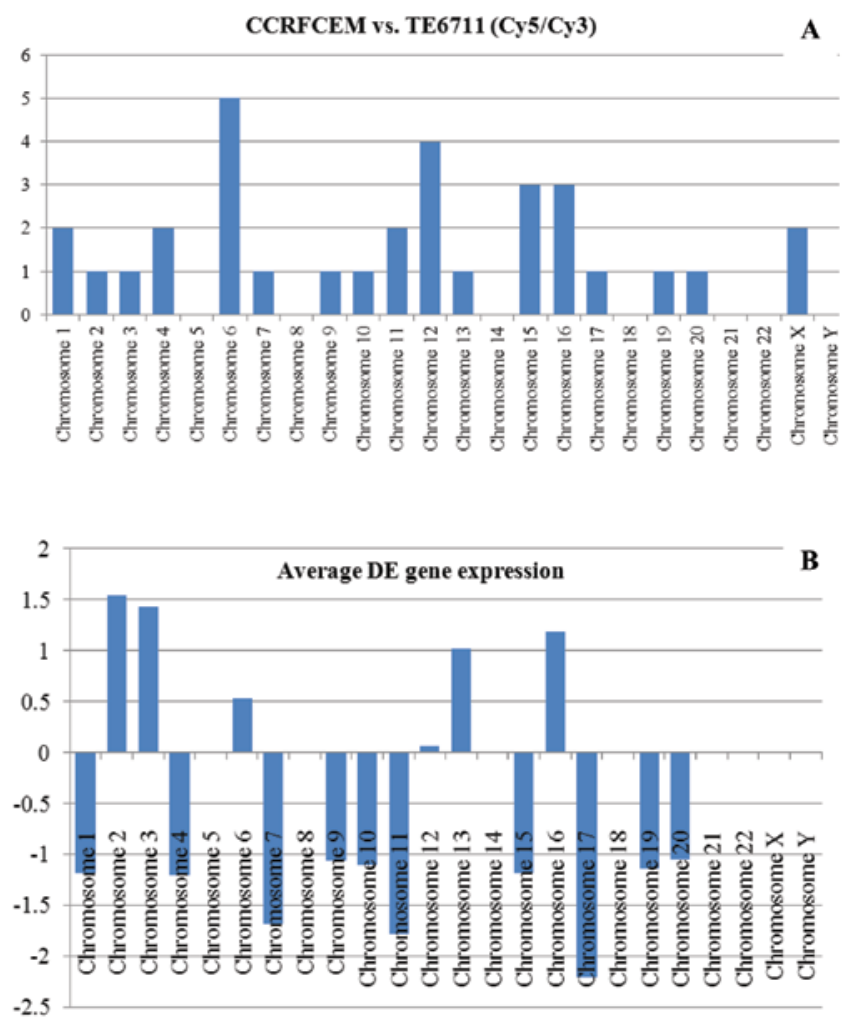

Figure 8. Chromosomal gene expression of the (A) DEGs and (B) average gene expression of the ratio Cy5/Cy3. DE, differentially expessed.

TFBMs. TFBM analysis was performed with the common DEGs between those significant for each channel and the gene
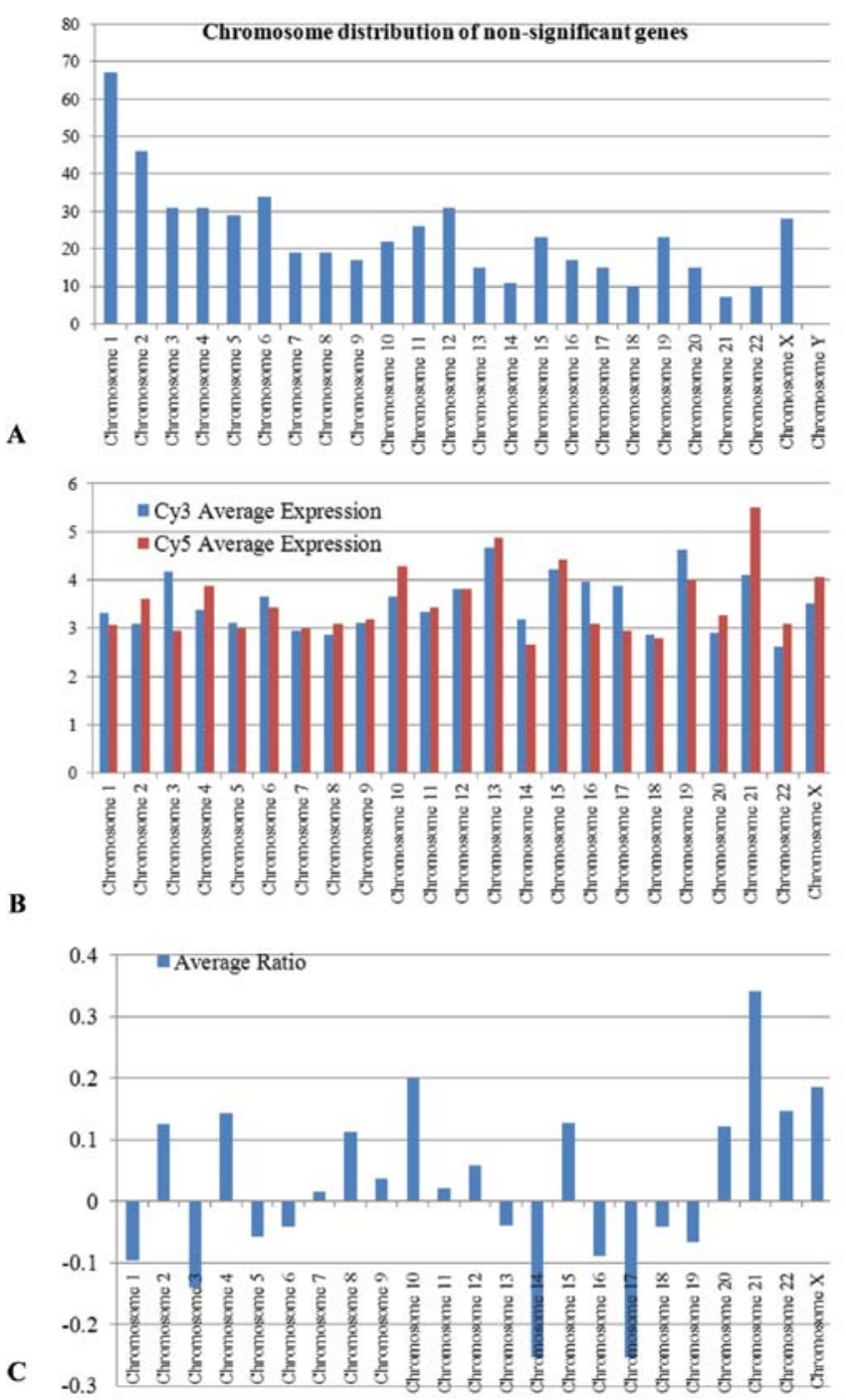

Figure 9. Chromosome distribution of (A) non-significant genes, (B) with average expression for each channel separately and (C) gene ratios.

ratios, as well as the non-significant genes between all comparisons. Analysis of the DEGs revealed 31 TFs with a FDR of $4 \%$ for $\mathrm{p}<0.01$ (Fig. 11A). In particular, an interesting case was the prediction of STAT6, which regulates DLC1 and WNT5A genes. Of these TFs, several displayed intriguing behavioral patterns, since they manifested an increased tendency in gene expression. Such examples were the RORA1, NFY and ERR1 TFs (Fig. 12). On the other hand, analysis of all common non-significant genes predicted 329 TFs with $\mathrm{p}<0.01$ and a FDR of $<1 \%$ (Fig. 11B). Attention was drawn to three TFs: STAT, GR and NFkB (Fig. 11C). These TFs regulate genes in the two cell types in the same manner, assuming that they play an equal role in gene regulation (Fig. 12). In particular, STAT is part of the JAK-STAT-MAPK pathway, which is considered to be of outermost importance in the regulation of carcinogenesis and tumor progression.

$G O$. GO analysis was used in order to approach the functionality of the DEGs. As previously described two gene groups were used: i) The DEGs for each channel separately as well as DEGs for samples ratio and ii) GO analysis for the commonly 

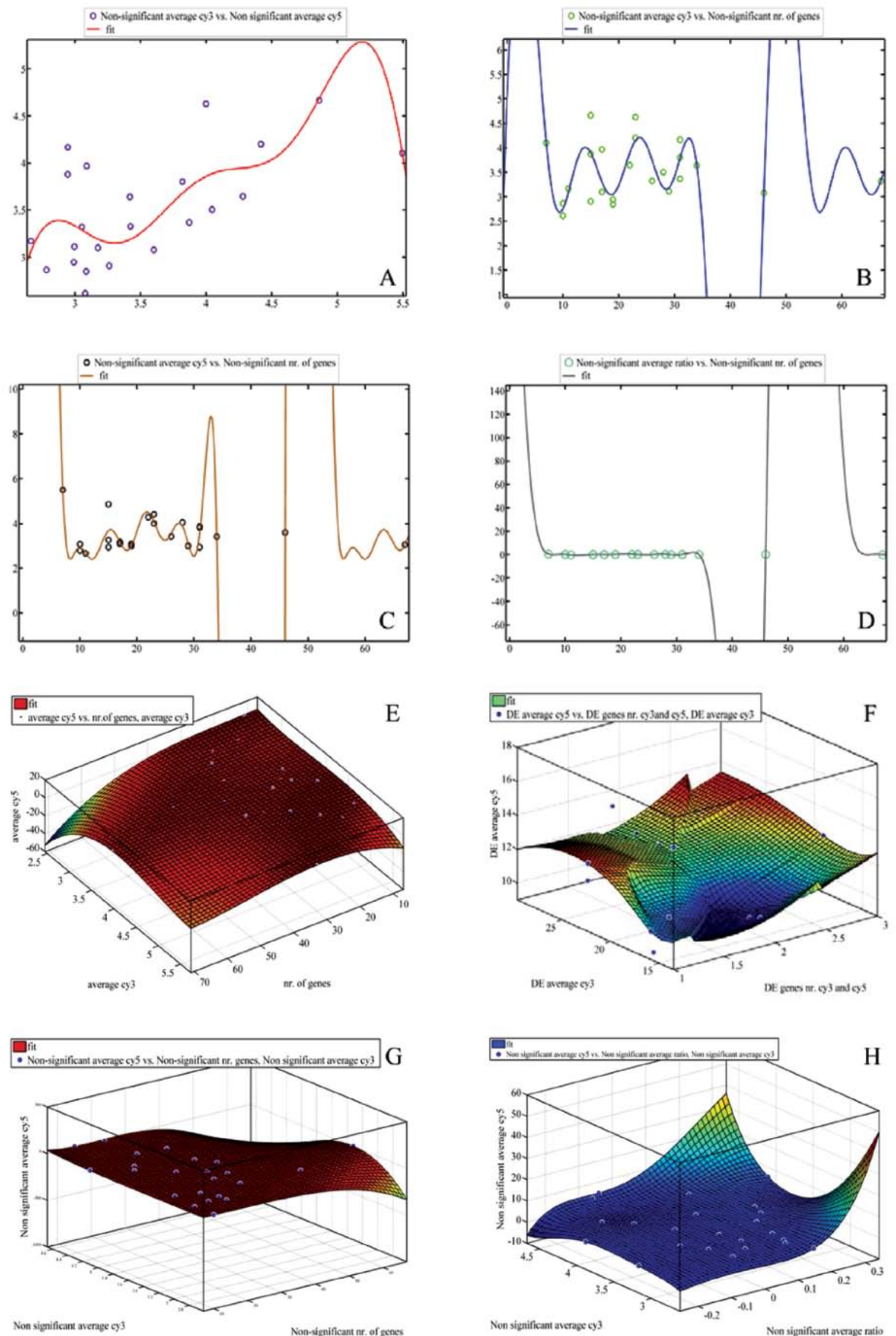

Figure 10. Fittings of chromosome distributions. (A) Curve fitting of the non-significant genes under Cy3 and non-significant genes under Cy5. (B) Curve fittings of non-significant genes under $\mathrm{Cy} 3$ and number of genes per chromosome. (C) Curve fittings of non-significant genes under Cy5 and number of genes per chromosome. (D) Curve fittings of non-significant genes ratios and number of genes per chromosome. (E) 3D fittings of average Cy5, number of genes and average Cy3. (F) 3D fittings of number of DEGs, average Cy5 and average Cy3 intensities. (G) 3D fittings of non-significant number of genes, non-significant average Cy5 and non-significant average Cy3 intensities. (H) 3D fittings of non-significant genes ratios, non-significant average Cy5 and non-significant average Cy3 intensities. 

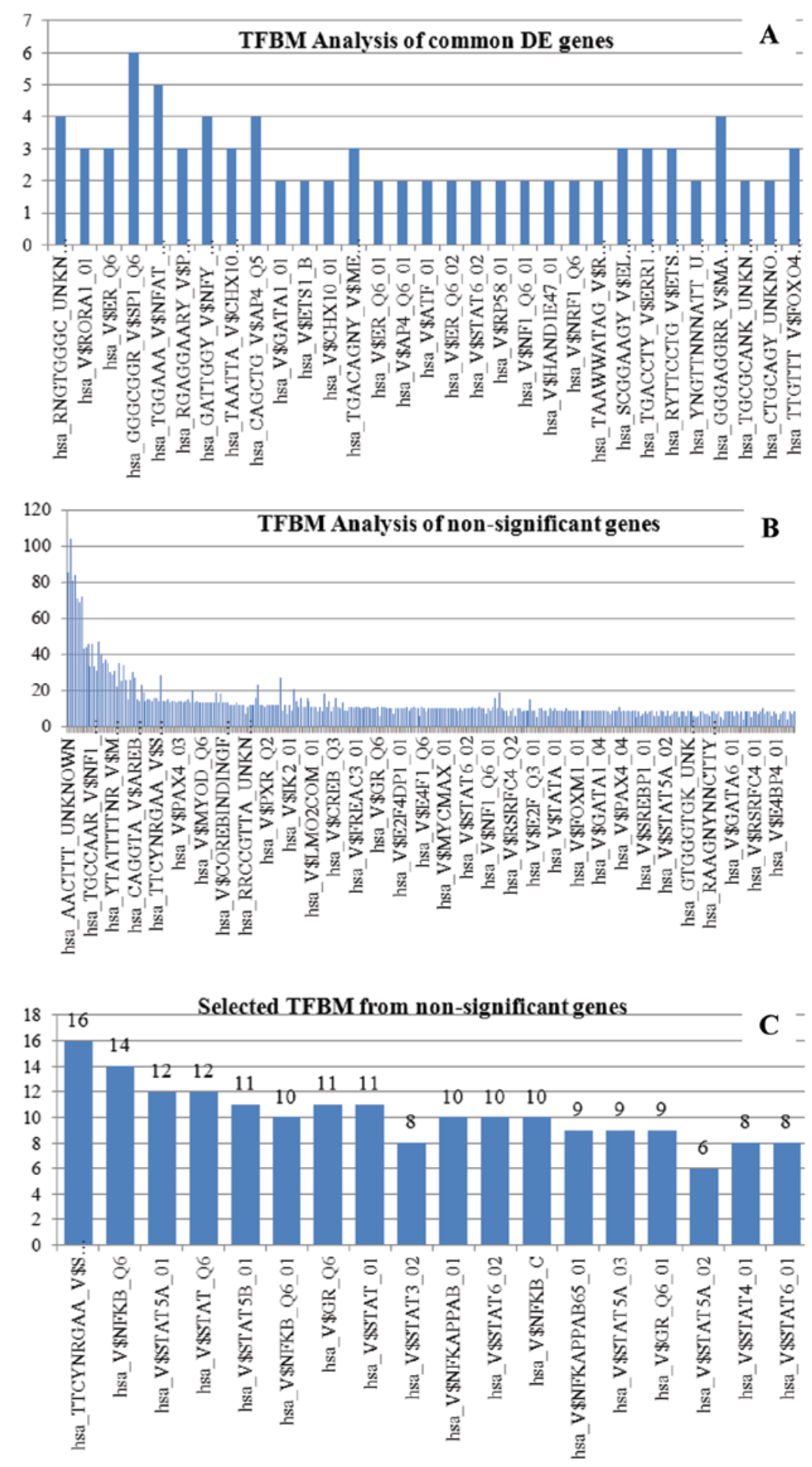

Figure 11. TFBM analysis of (A) common DEGs as well as (B and C) non-significant genes. DE, differentially expessed.

non-significant genes. GO relations for the general categories of biological process, cellular compartment and molecular function are presented in Fig. 13A and B. DEGs were predicted to participate in two main functions $(\mathrm{p}<0.01)$, receptor binding and cytokine receptor binding (Fig. 13A). The detailed list of DEGs and GO entities prediction is presented in Table II. On the other hand, the non-significant genes consisted a larger dataset and we expected to find more predicted functions.
The genes of interest were those that participate in biological process, particularly in proliferation, cell cycle, differentiation, communication (extracellular cell-cell signaling) and embryonal development.

Genes were divided into nine major categories based on their function and unchanged expression profiles: i) Secretion molecule genes: CGRRF1, IGFBP7, PDGFB, PRC1, TGFB3 and VEGFC, ii) receptor/receptor binding/cytokine activity 

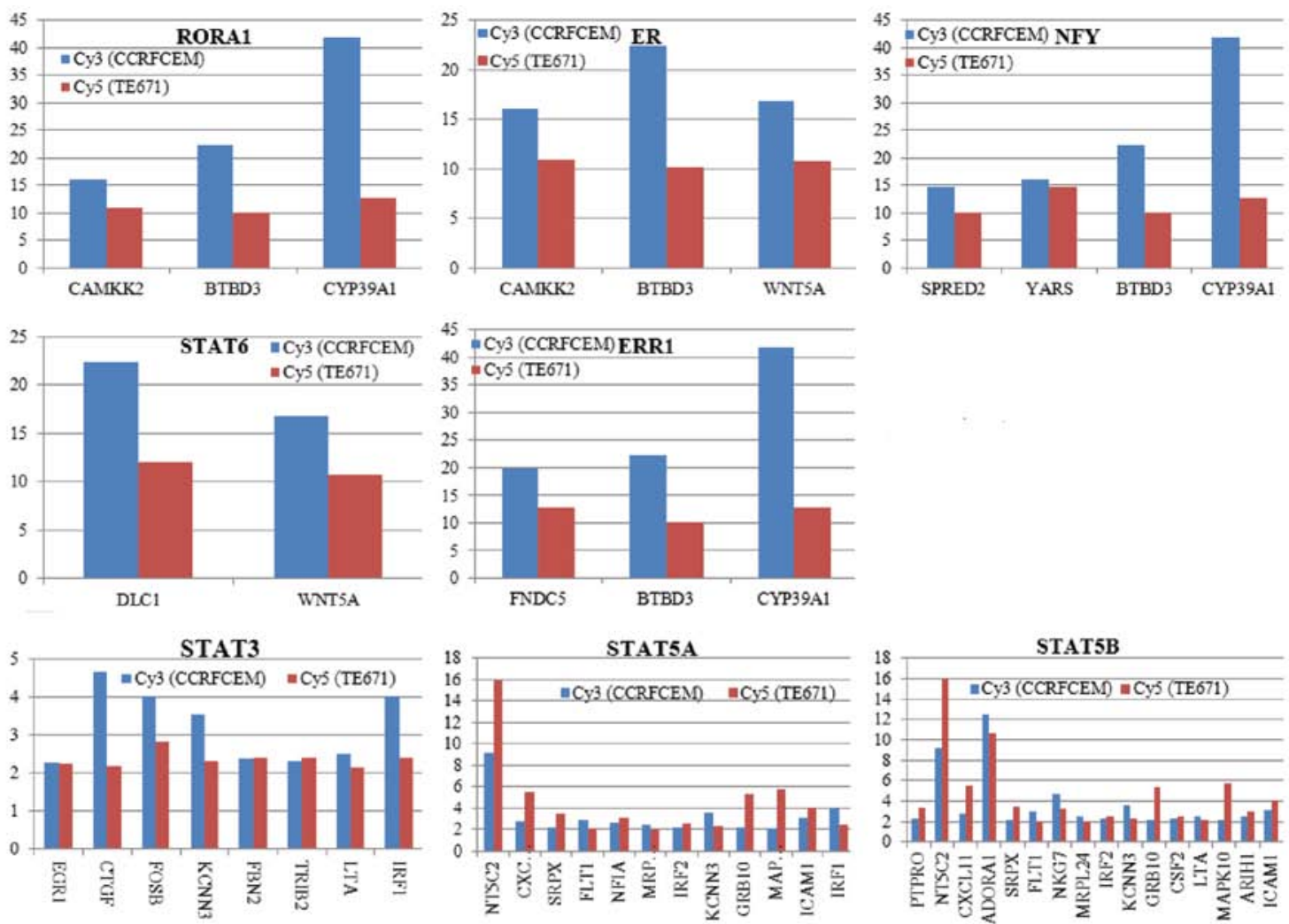

STAT5A

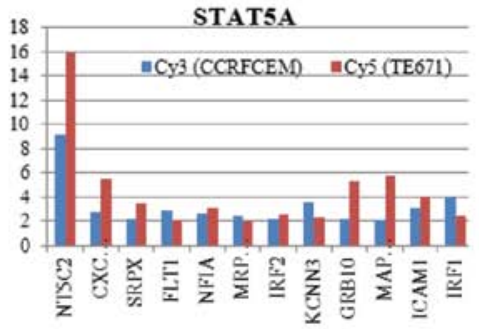

STAT5B
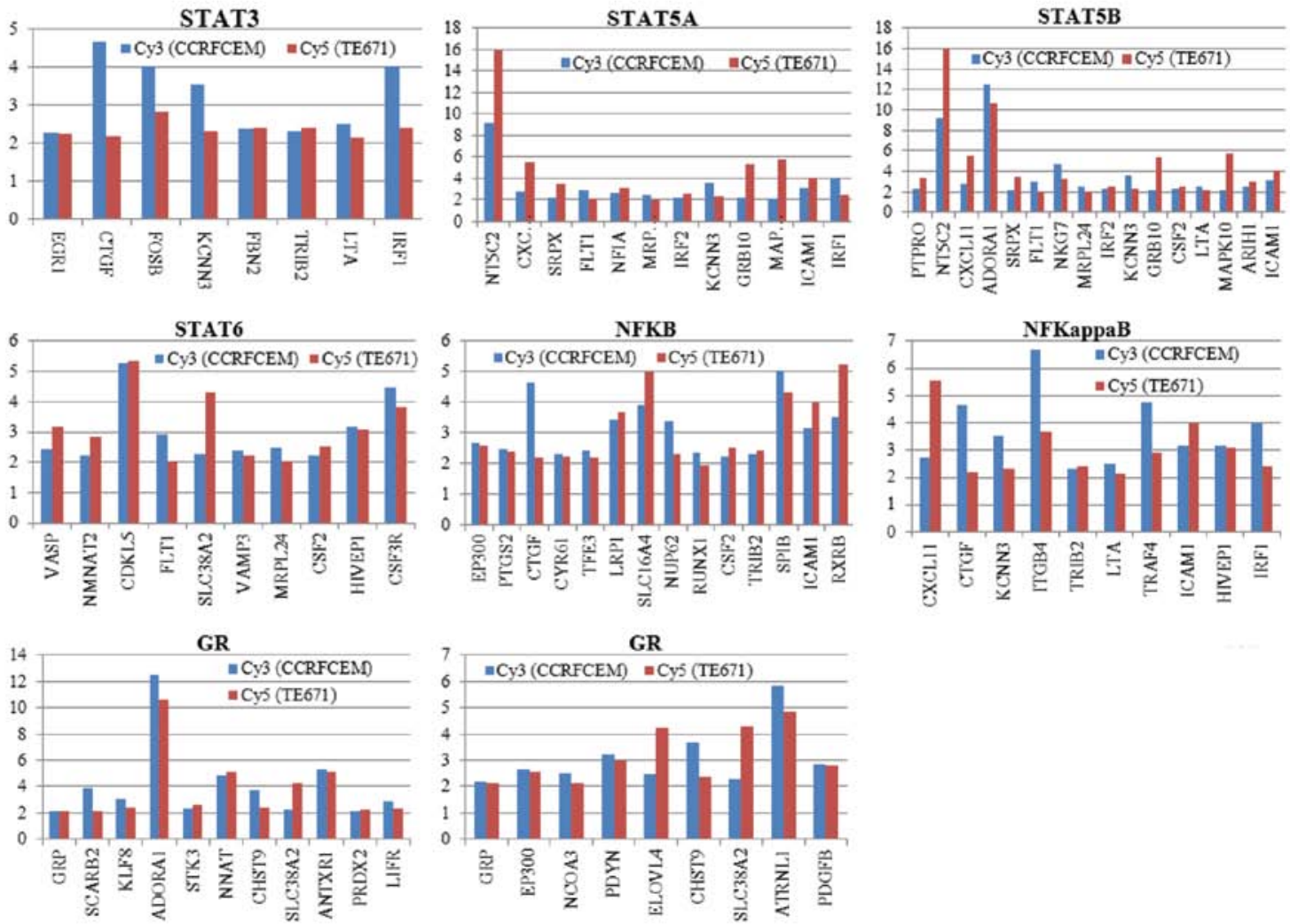

Figure 12. TFs of common non-significant genes. Emphasis was given to STAT, GR and NF-кB.

Table II. GO functions of differentially expressed genes.

Molecular function - cytokine receptor binding - GO:0005126 $\mathrm{C}=178 ; \mathrm{O}=3 ; \mathrm{E}=0.22 ; \mathrm{R}=13.63 ; \operatorname{raw} \mathrm{P}=0.0013 ; \operatorname{adj} \mathrm{P}=0.0377$

FEM1B $\quad 10116 \quad$ ENSG00000169018

$\begin{array}{lll}\text { SPRED2 } & 200734 & \text { ENSG00000198369 }\end{array}$

YARS $\quad 8565 \quad$ ENSG00000134684

FEM1B Fem-1 homolog b (C. elegans)

Molecular function - receptor binding - GO:0005102

SPRED2

Sprouty-related, EVH1 domain containing 2

$\mathrm{C}=856 ; \mathrm{O}=5 ; \mathrm{E}=1.06 ; \mathrm{R}=4.72 ; \operatorname{rawP}=0.0032 ; \operatorname{adj} \mathrm{P}=0.0464$

$\begin{array}{lll}\text { FEM1B } & 10116 & \text { ENSG00000169018 } \\ \text { SPRED2 } & 200734 & \text { ENSG00000198369 } \\ \text { YARS } & 8565 & \text { ENSG00000134684 } \\ \text { NPFF } & 8620 & \text { ENSG00000139574 } \\ \text { WNT5A } & 7474 & \text { ENSG00000114251 }\end{array}$

FEM1B

SPRED2

YARS

NPFF

WNT5A

Tyrosyl-tRNA synthetase 

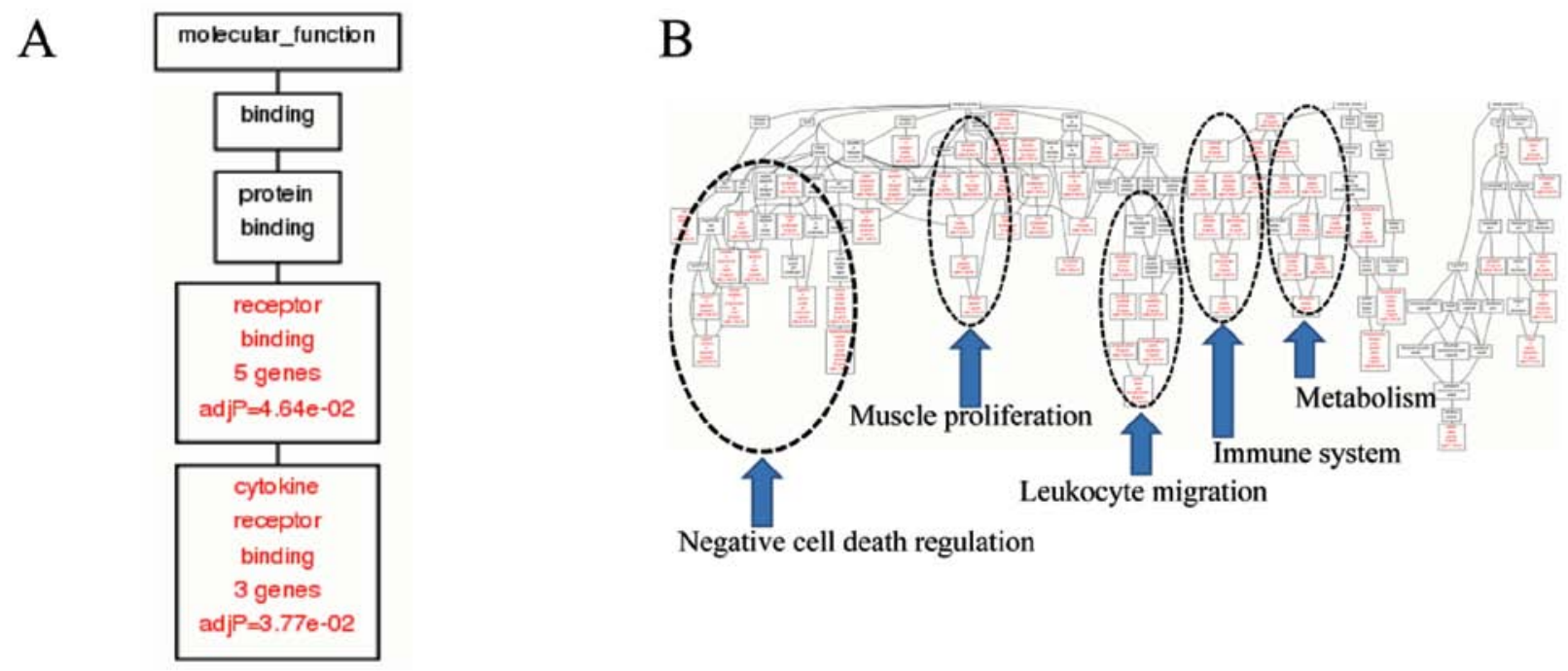

Figure 13. GO terms prediction for (A) DEGs and (B) non-significant genes.

genes: PDGFB, TGFB3, VEGFC, ADORA1, ALCAM, AVPR1A, CCRL1, CD40LG, CNR1, CSF3R, GABRA2, GLRA3, GPR44, HTR2B, IL2RA, IL9, LIFR, LRP1, MET, NPFF, PDYN, PTPN13, PTPN9, PTPRCAP, RXRB, SPRED2, TFRC, TLR3 and TRIP13, iii) cell communication/cell-cell signaling genes: TGFB3, GABRA2, HTR2B, LIFR, NPFF, PDYN, SPRED2, ARHGAP6, CDC2, DDEF1, DDEF2, EFA6R, GNG12, KIAA0974, PLEKHG1, PSMA4, RAPGEF2, RUNDC3A, TIAM1 and TMEPAI, iv) cell cycle genes, including genes for mitosis regulation and cell cycle process, such as: CDC2, PRC1, AK021716, DLGAP5, H2AFV, PPAPDC1B and ZZEF1, v) cell proliferation genes: CDC2, GNL3 and PDGFB, vi) cell differentiation/developmental/ embryonic process genes: CDC2, VEGFC, CD40LG, IL2RA, ANXA4, BNIP3L, CD36, CFDP1, CUL7, FEM1B, FOXO1, MAB21L1, MBNL3, MMP2, NNAT, NP25, PDCD5, PDLIM7, PLAC1, RPS6KA3, RTTN, TCL1A, THBS4 and ZNF313, vii) stem cell/stem cell differentiation-related genes: $\mathrm{CDC} 2$, VEGFC, CD40LG, IL2RA, ANXA4, CFDP1, CUL7, FOXO1, MMP2, NNAT, NP25, PDCD5, PDLIM7, TCL1A, PDGFB, PRC1, DLGAP5, TGFB3, GABRA2, HTR2B, LIFR, NPFF, ARHGAP6, DDEF2, ADORA1, CCRL1, CNR1, CSF3R, GPR44, IL9, LRP1, MET, PTPN13, PTPN9, PTPRCAP, RXRB, TFRC, TLR3, CGRRF1, IGFBP7, FOSB, SIRT5 and TCF4. Also, in order to investigate the presence of negative or positive regulatory mechanisms, two more gene groups which are negative and positive regulators of cellular processes, were studied: ANXA4, CD36, FOSB, SIRT5 and TCF4 (negative regulatory genes) and FEM1B (positive regulator), viii) negative cell death regulatory genes: IL7, ADAM17, ACVR1, TNFAIP3, ANXA4, DHCR24, LRP1, BNIP3L, SELS, CSF2, NAIP, GSTP1, HMOX1, BARD1, PRDX2, CDC2, XRCC5, FNTA, ADORA1, PTEN, CFDP1, TGFB3, IGF1, DAPK1, MSH2, NUP62, CDKN2D, KIT and LIFR, ix) muscle proliferation genes, which is noteworthy as these genes are common to both cell types: IFNG, PTGS2, TGFBR3, ANG, FLT1, STAT1, IGF1, TGFB2, PDGFB and IL12B, $x$ ) genes involved in leukocyte migration, again an interesting observation as this function is common to both cell types: IFNG, ADAM17, ADORA1, SELP, ITGA6, IL8, TGFB2, CD34, HMOX1, PDGFB and ICAM1 and xi) genes involved in metabolism: PTPRO, MTM1, ACVR1, PTPRA, NTRK3, NDUFAB1, PDGFB, MAPK14, FLT3, BARD1, CDKN2C, RPS6KA2, TGFBR3, CDKL5, IGF1, EPHB6, MET, FGF23, MAP3K10, CDKN2D, GPD1L, KIT, IFNG, TNK2, PTPN9, TLK1, LRP1, KALRN, CDC2, ATP5F1, DCLK1, FLT1, MADD, STAT1, PPP1CB, MAPK13, MAPK10, PARD3, DYRK3, NDUFS1, TRIB2, TGFB2, INPP1, PIP4K2A, ADORA1, ANG, STK3, FLT4, PTEN, MSH2, DAPK1, TGFB3, SYNJ2, CSNK2A2, MORC3, VEGFC, PDGFC, ADAM17, PIK3C3, MAPKAPK3, PTPN13, CSF2, PRDX2, DOCK7, FGR, PGK1, TIE1, NUP62, STK25, CCL11, RPS6KA3 and CSF1R. The detailed results of the GO analysis for non-significant genes are presented in Table III. The tables is presented in such a way that the overlapping functions of genes is shown. We focused on genes specific for leukemia and RMS, and their relations to secretion, receptors, cell cycle, cell proliferation, cell differentiation and cell death regulation. Genes shown in bold are those considered to be unchanged or equally regulated in both cell types.

Pathway analysis. In order to understand the common mechanics of the two different types of cancer and find potential oncogenic drivers, a pathway analysis was applied. The purpose was to identify genes that participate in various pathways and the way they interact among them. Due to the complexity of the pathways and the transcripts revealed by the microarrays, we used the following approach for this analysis: First, genes were separated in two categories (DEGs and non-significant genes). Second, using the Pathway Explorer and WebGestalt tools, we explored the occurrence of the genes revealed in the microarrays, in known pathways from all available databases. DEGs revealed one significant pathway, the JAK-STAT-MAPK pathway ( $\mathrm{p}<0.01)$, with the participation of SPRED2 and IL2RA. On the other hand, the non-significant genes were predicted to participate in a plethora of pathways (Fig. 14). An overview of the pathway predictions based on the KEGG pathway 


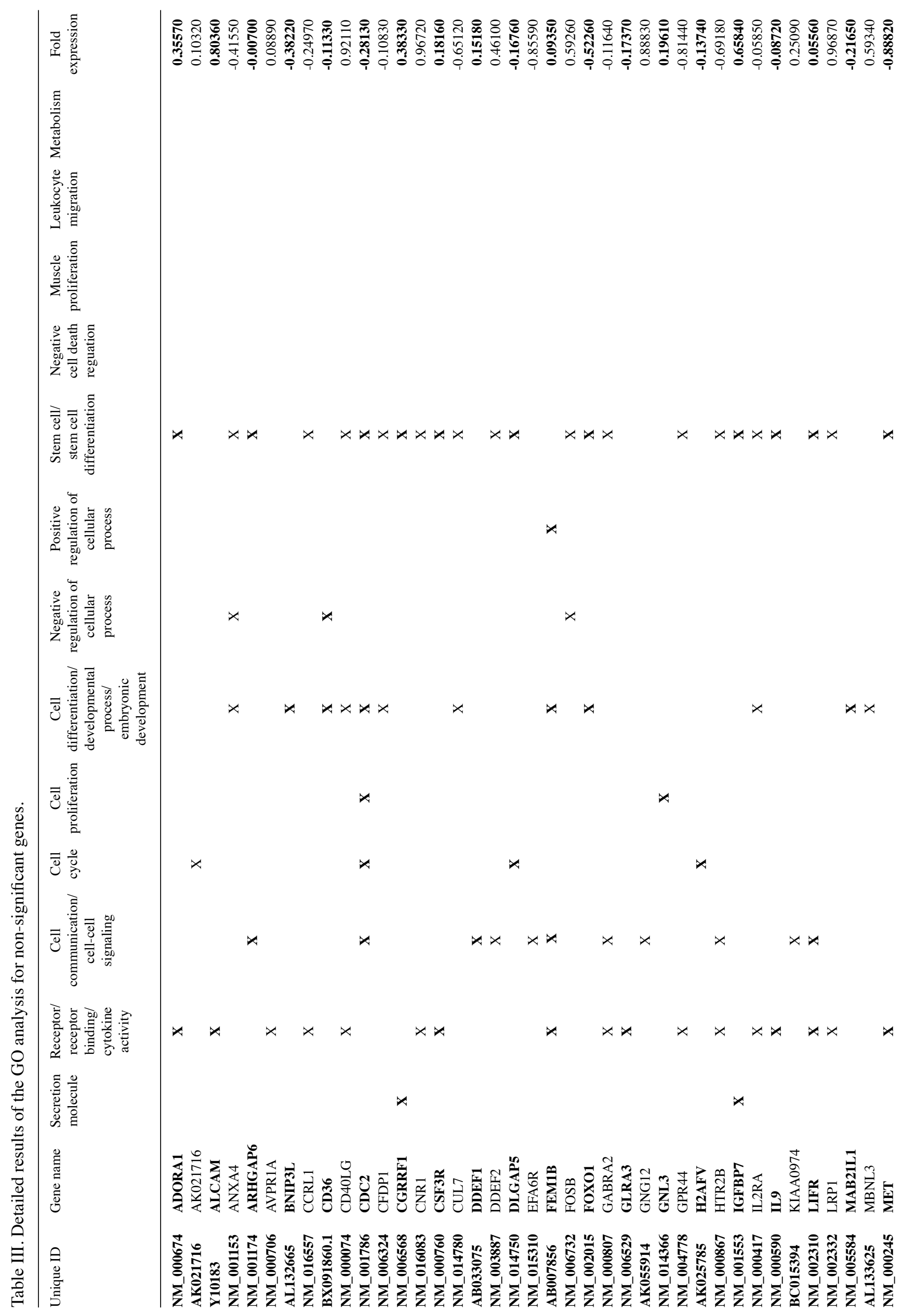




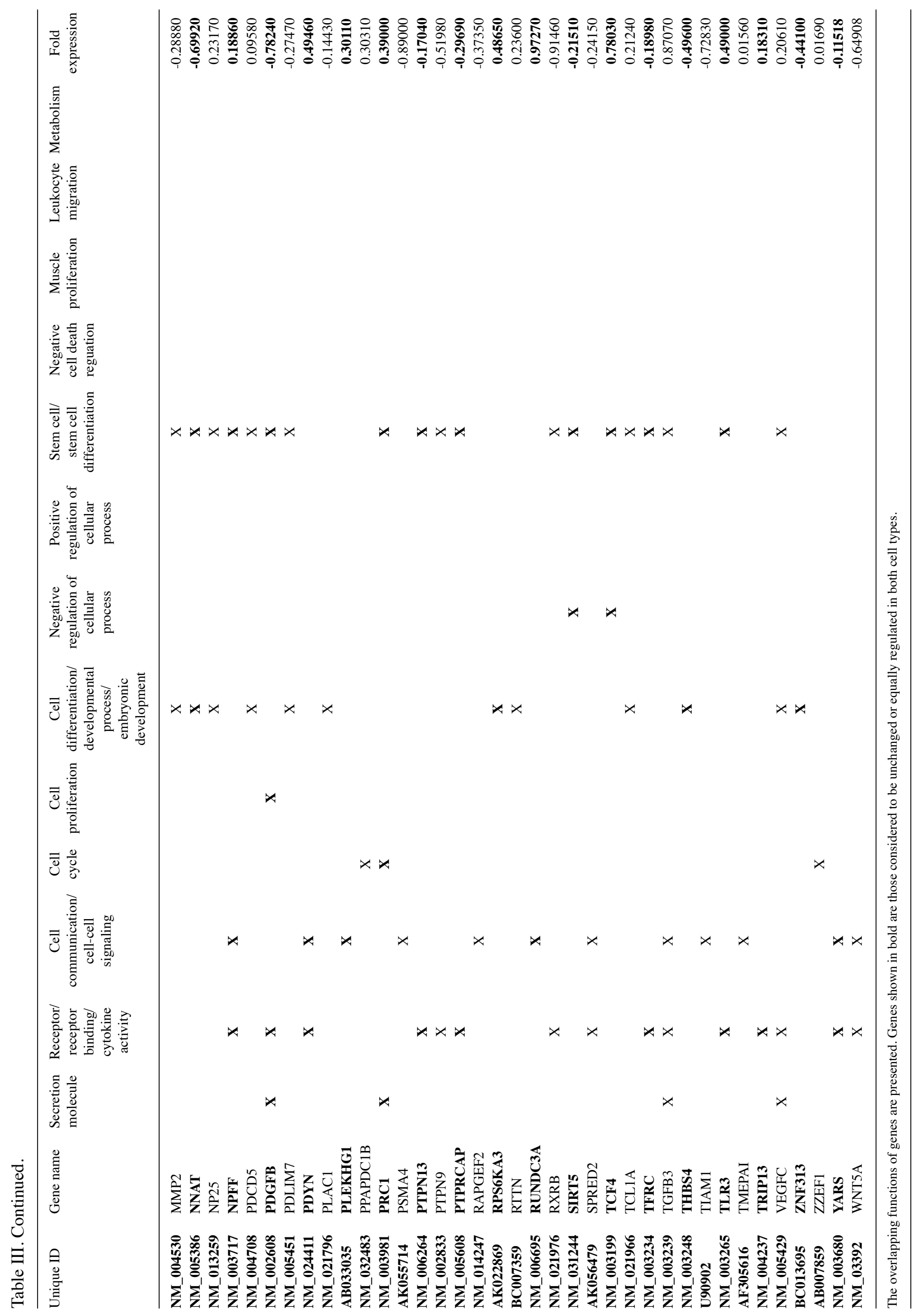




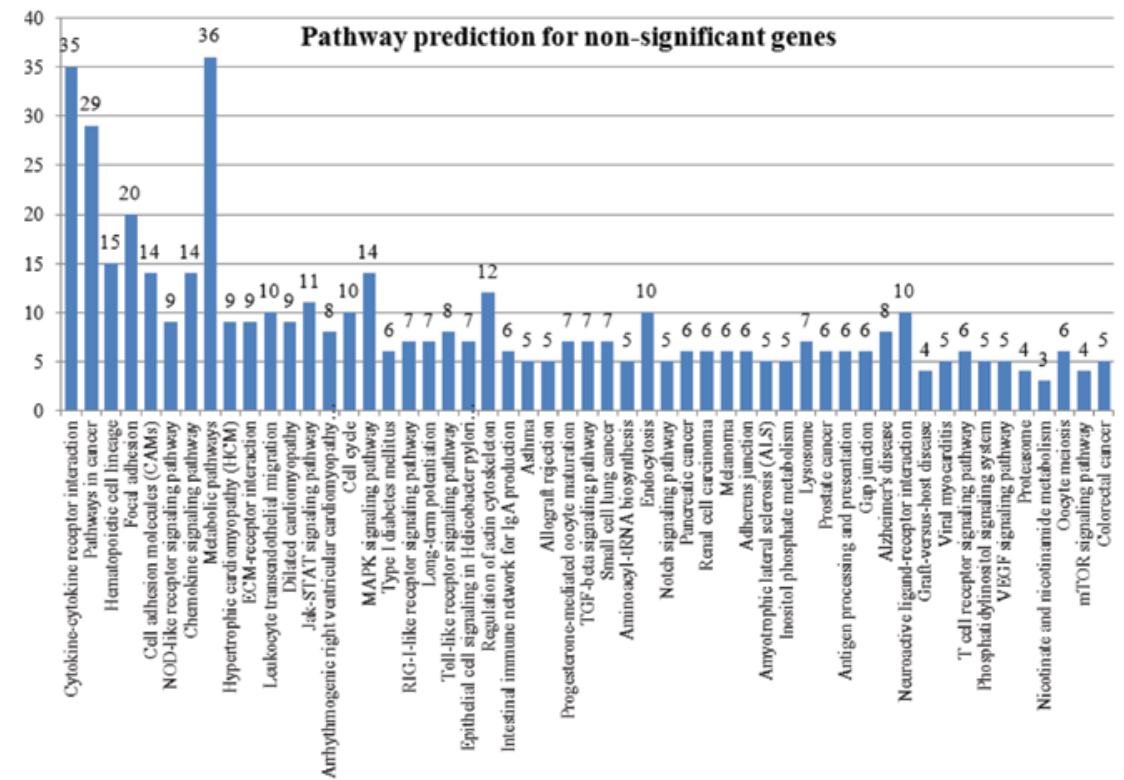

Figure 14. Prediction of pathway participation of non-significant genes. Numbers over the bars indicate the numbers of genes found on each pathway with a $99 \%$ confidence interval.

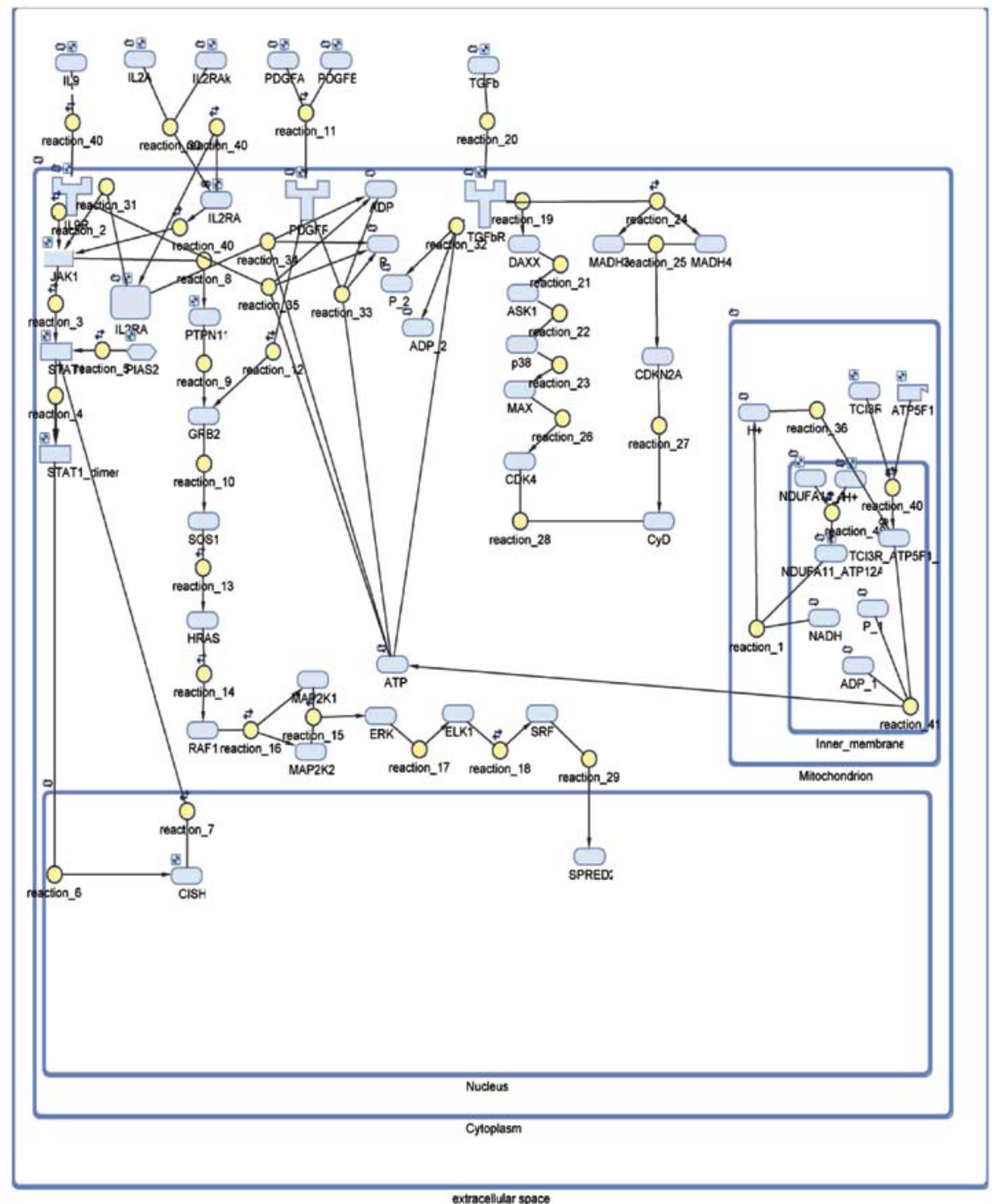

Figure 15. Diagrammatic view of the coupled pathways used for simulation. 
database and the pathways of interest are depicted in Table IV. Thereafter, we analyzed the common presence of extracellular signal molecules. The two cell types share three main axons of signaling, for cell cycle regulation and cell proliferation, among others: i) an ECM-receptor/focal adhesion/MAPK signal transduction pathway, ii) a cytokine-cytokine-receptor/MAPK/ cell cycle signal transduction pathway, iii) cell death regulatory mechanisms and iv) a JAK-STAT/MAPK signal transduction pathway. All these combinations participate in cell proliferation, differentiation, cell fate determination and anti-apoptosis. In order to gain further insight into gene regulatory mechanisms common to both cell types, we performed a pathway simulation including genes of interest from all pathways. Furthermore, we attempted to model the investigated pathways using simulations. We created a coupled pathway, which included the JAK-STAT, MAPK, TGF- $\beta$ signaling pathways and basic metabolism pathways (Fig. 15). Further simulations of the pathway manifested very interesting results. Four molecules appeared to manifest oscillations in their behavior: JAK, STAT1 and PIAS2 (part of the JAK-STAT pathway) and CDK4 (part of the TGF- $\beta$ pathway) (Fig. 16A). It appeared that these molecules followed rapid oscillatory dynamics and without an inhibitory mechanism, they constitute potential drivers of cellular proliferation. It is suggested that these four molecules are possible oncogenic drivers in the cell systems under study. Of note, our microarray analysis revealed that these four genes participate similarly in the two cell types. Since we defined the initial dynamics of these molecules, we investigated whether they follow linear or non-linear dynamics, and whether further correlations exist among them. In order to do so, we used state-space plots of combinations of the 4 genes. Of note, plotting JAK1 vs. STAT1 showed that they follow very complicated dynamics, which actually resemble a repeller or a 'source' (Fig. 16B). Similar behavior was manifested by the comparison of PIAS2 with STAT1 (Fig. 16C) and PIAS2 with JAK1 (Fig. 16D). Also, we observed that JAK1 vs. STAT1 and PIAS2 vs. JAK1 are almost mirror images of each other. On the contrary, plotting CDK4 vs. JAK1 did not reveal similar behavior, revealing a 'sink' effect that common drivers tend to collide (Fig. 16E). These results point towards chaotic phenomena (in terms of chaos dynamics). Further investigation is required in order to futher analyze the dynamics revealed in this study and clarify this phenomenon.

In order to examine the synergistic effects of the molecules, we simulated the sum these molecules with respect to time. Of note, the sum of STAT1 and JAK1 (Fig. 16F) manifested very similar behavior with the sum of PIAS2 and STAT1 (Fig. 16G), indicating that these molecules are possibly key molecules to the pathway function. Once again, the sum of JAK1 and STAT1 (Fig. 16F) was a mirror image to the sum of JAK1 and PIAS2 (Fig. 16H). Finally, the simulation of the sum of JAK1 and CDK4 indicated that it leads the system to an oscillatory behavior tending to infinity (Fig. 16I). This reinforces the role of the JAK1 and CDK4 molecules as potential oncogenic drivers of the cell types presented in our study.

\section{Discussion}

In the present study, we used computational and system biology approaches in order to investigate the following: i) In a certain gene set, genes that are specific to each cell type and at the same time common to both cell types, ii) similarities in tumor progression, cell cycle and secretory extracellular signaling, iii) common regulatory mechanisms for the two cell types, based on their expression profiles, iv) pathways common to both cell types, and v) evidence of the role of stem cells in tumorigenesis. For this purpose, we analyzed different signaling pathways and searched for the most prevalent pathway in the progression of the two cell types.

ALL and RMS are two malignancies originating from different cell types (a lymphoblast and a myoblast, respectively), although they both are of mesodermal origin. Understanding the origin of tumors on the 'poiesis' level, such as hemopoiesis/ lymphopoiesis (76) or myogenesis, may lead to the discovery of new therapeutic targets. Therefore, we hypothesized that the two cell types possess common characteristics, first due to their common developmental origin and second, due to their malignant character. Therefore, we used microarrays and a bioinformatics approach in order to examine whether common genes that participate in critical cellular pathways exist between the two cell types.

\section{Cytokine/cytokine interactions}

Interleukins. Our analysis predicted 35 unique targets mapped on the cytokine/cytokine-receptor pathway. Cytokines are significant molecules participating in hemopoietic stem cell differentiation. In particular, $\gamma$ interleukins were reported to have proliferative and differentiating effects on T-ALL primary cells (77). Despite the differences between normal blood stem cells and malignant ones, they both use cytokine signaling for progression and differentiation (78). Our analysis predicted IL8, IL9 and the IL2 receptor.

Chemokines. None of the CXCL or CXCR family of molecules appeared to have similar expression. It has been previously reported that in order for certain cell lines to produce these chemokines, the constitutive presence of $\mathrm{NF}-\kappa \mathrm{B}$ in the nucleus is required (79). The CCRF-CEM cells have shown that $N F-\kappa B$ is constitutively present in the nucleus (data not shown) supporting the evidence of chemokine expression. The fact that the NF- $\kappa \mathrm{B}$ factor was predicted from TFBM analysis supports this hypothesis.

Hematopoietins. The two cell types seem to share a common expression profile for the LIFR gene. The LIFR protein participates in embryo implantation, in the differentiation of neural stem cells to astrocytes (80), as well as in the mesenchyme to epithelial conversion (81). Its role has been reported to be connected to the PTEN-Akt-FOXO axis and STAT3 (80). So far, there are no reports of the role of LIFR in ALL or RMS; its role is yet unclear in the present system. Another interesting gene our analysis predicted is CSF3R. It has been reported for its role in hematopoiesis, since it is expressed only in the myeloid lineages of hematopoietic cells (82). There are no reports linking CSF3R to RMS. However, a common developmental mechanism utilized by both cell types for their progression and growth, could exist.

PDGF family. Our study predicted that within the PDGF family, the two cell types share a common expression profile for the secretory molecules, PDGFB and VEGFC; as well as for the receptors, MET and FLT3. PDGF regulates clonal proliferation in pre-B cell lines and it has been found to be overexpressed in B-chronic leukemia (83). It has also been 
Table IV. Prediction of pathway participation of non-significant genes at a $99 \%$ confidence interval.

KEGG pathway - cytokine-cytokine receptor interaction - 04060

$\mathrm{C}=267 ; \mathrm{O}=35 ; \mathrm{E}=3.44 ; \mathrm{R}=10.18$; rawP=1.28e-24; adjP=1.42e-22

\begin{tabular}{|c|c|c|c|}
\hline ACVR1 & 90 & ACVR1 & Activin A receptor, type I \\
\hline XCL1 & 6375 & XCL1 & Chemokine (C motif) ligand 1 \\
\hline TGFB2 & 7042 & TGFB2 & Transforming growth factor $\beta 2$ \\
\hline TNFSF8 & 944 & TNFSF8 & Tumor necrosis factor (ligand) superfamily, member 8 \\
\hline CXCR3 & 2833 & CXCR3 & Chemokine (C-X-C motif) receptor 3 \\
\hline FLT3 & 2322 & FLT3 & Fms-related tyrosine kinase 3 \\
\hline PDGFB & 5155 & PDGFB & Platelet-derived growth factor $\beta$ polypeptide [simian sarcoma viral ( $\mathrm{v}$-sis) oncogene homolog] \\
\hline CSF3R & 1441 & CSF3R & Colony stimulating factor 3 receptor (granulocyte) \\
\hline CCL26 & 10344 & CCL26 & Chemokine (C-C motif) ligand 26 \\
\hline FLT4 & 2324 & FLT4 & Fms-related tyrosine kinase 4 \\
\hline CCL8 & 6355 & CCL8 & Chemokine (C-C motif) ligand 8 \\
\hline TGFB3 & 7043 & TGFB3 & Transforming growth factor $\beta 3$ \\
\hline CD70 & 970 & $\mathrm{CD} 70$ & CD70 molecule \\
\hline MET & 4233 & MET & Met proto-oncogene (hepatocyte growth factor receptor) \\
\hline KIT & 3815 & KIT & V-kit Hardy-Zuckerman 4 feline sarcoma viral oncogene homolog \\
\hline IL7 & 3574 & IL7 & Interleukin 7 \\
\hline IFNG & 3458 & IFNG & Interferon $\gamma$ \\
\hline VEGFC & 7424 & VEGFC & Vascular endothelial growth factor $\mathrm{C}$ \\
\hline PDGFC & 56034 & PDGFC & Platelet derived growth factor $\mathrm{C}$ \\
\hline CXCL13 & 10563 & CXCL13 & Chemokine (C-X-C motif) ligand 13 \\
\hline IFNGR2 & 3460 & IFNGR2 & Interferon $\gamma$ receptor 2 (interferon $\gamma$ transducer 1) \\
\hline CCL20 & 6364 & CCL20 & Chemokine (C-C motif) ligand 20 \\
\hline CNTFR & 1271 & CNTFR & Ciliary neurotrophic factor receptor \\
\hline IL9 & 3578 & IL9 & Interleukin 9 \\
\hline CSF2 & 1437 & CSF2 & Colony stimulating factor 2 (granulocyte-macrophage) \\
\hline IL12B & 3593 & IL12B & Interleukin 12B (natural killer cell stimulatory factor 2 , cytotoxic lymphocyte maturation factor $2, \mathrm{p} 40$ ) \\
\hline CXCL11 & 6373 & CXCL11 & Chemokine (C-X-C motif) ligand 11 \\
\hline IL8 & 3576 & IL8 & Interleukin 8 \\
\hline FLT1 & 2321 & FLT1 & Fms-related tyrosine kinase 1 (vascular endothelial growth factor/vascular permeability factor receptor) \\
\hline CXCL1 & 2919 & CXCL1 & Chemokine (C-X-C motif) ligand 1 (melanoma growth stimulating activity $\alpha$ ) \\
\hline IL17A & 3605 & IL17A & Interleukin $17 \mathrm{~A}$ \\
\hline LTA & 4049 & LTA & Lymphotoxin $\alpha$ (TNF superfamily, member 1$)$ \\
\hline CCL11 & 6356 & CCL11 & Chemokine (C-C motif) ligand 11 \\
\hline LIFR & 3977 & LIFR & Leukemia inhibitory factor receptor $\alpha$ \\
\hline CSF1R & 1436 & CSF1R & Colony stimulating factor 1 receptor \\
\hline
\end{tabular}

KEGG pathway - pathways in cancer - 05200

$\mathrm{C}=330 ; \mathrm{O}=29 ; \mathrm{E}=4.25 ; \mathrm{R}=6.82 ; \operatorname{rawP}=7.35 \mathrm{e}-16$; $\operatorname{adj} \mathrm{P}=4.08 \mathrm{e}-14$

\begin{tabular}{|c|c|c|c|}
\hline VEGFC & 7424 & VEGFC & Vascular endothelial growth factor $\mathrm{C}$ \\
\hline EP300 & 2033 & EP300 & E1A binding protein $\mathrm{p} 300$ \\
\hline LAMA4 & 3910 & LAMA4 & Laminin, $\alpha 4$ \\
\hline COL4A2 & 1284 & COL4A2 & Collagen, type IV $\alpha 2$ \\
\hline ITGA6 & 3655 & ITGA6 & Integrin $\alpha 6$ \\
\hline CTNNA1 & 1495 & CTNNA1 & Catenin (cadherin-associated protein) $\alpha 1,102 \mathrm{kDa}$ \\
\hline TGFB2 & 7042 & TGFB2 & Transforming growth factor $\beta 2$ \\
\hline GSTP1 & 2950 & GSTP1 & Glutathione S-transferase pi 1 \\
\hline FLT3 & 2322 & FLT3 & Fms-related tyrosine kinase 3 \\
\hline PDGFB & 5155 & PDGFB & Platelet-derived growth factor $\beta$ polypeptide [simian sarcoma viral (v-sis) oncogene homolog] \\
\hline CTNNA2 & 1496 & CTNNA2 & Catenin (cadherin-associated protein) $\alpha 2$ \\
\hline CSF3R & 1441 & CSF3R & Colony stimulating factor 3 receptor (granulocyte) \\
\hline RXRB & 6257 & RXRB & Retinoid X receptor $\beta$ \\
\hline PTGS2 & 5743 & PTGS2 & Prostaglandin-endoperoxide synthase 2 (prostaglandin G/H synthase and cyclooxygenase) \\
\hline PTEN & 5728 & PTEN & Phosphatase and tensin homolog \\
\hline WNT5B & 81029 & WNT5B & Wingless-type MMTV integration site family, member 5B \\
\hline IL8 & 3576 & IL8 & Interleukin 8 \\
\hline STAT1 & 6772 & STAT1 & Signal transducer and activator of transcription $1,91 \mathrm{kDa}$ \\
\hline IGF1 & 3479 & IGF1 & Insulin-like growth factor 1 (somatomedin $\mathrm{C}$ ) \\
\hline DAPK1 & 1612 & DAPK1 & Death-associated protein kinase 1 \\
\hline MSH2 & 4436 & MSH2 & MutS homolog 2, colon cancer, nonpolyposis type 1 (E. coli) \\
\hline TGFB3 & 7043 & TGFB3 & Transforming growth factor $\beta 3$ \\
\hline RUNX1 & 861 & RUNX1 & Runt-related transcription factor 1 \\
\hline
\end{tabular}


Table IV. Continued.

\begin{tabular}{llll}
\hline MET & 4233 & MET & Met proto-oncogene (hepatocyte growth factor receptor) \\
MAPK10 & 5602 & MAPK10 & Mitogen-activated protein kinase 10 \\
FGF23 & 8074 & FGF23 & Fibroblast growth factor 23 \\
KIT & 3815 & KIT & V-kit Hardy-Zuckerman 4 feline sarcoma viral oncogene homolog \\
TRAF4 & 9618 & TRAF4 & TNF receptor-associated factor 4 \\
CSF1R & 1436 & CSF1R & Colony stimulating factor 1 receptor \\
KEGG pathway - hematopoietic cell lineage -04640 & \\
C=88; O=15; E=1.13; R=13.23; rawP=4.99e-13; adjP=1.85e-11 \\
HLA-DRB1 & 3123 & HLA-DRB1 & Major histocompatibility complex, class II, DR $\beta 1$ \\
IL7 & 3574 & IL7 & Interleukin 7 \\
CD8A & 925 & CD8A & CD8a molecule \\
ITGA4 & 3676 & ITGA4 & Integrin $\alpha 4$ (antigen CD49D, $\alpha 4$ subunit of VLA-4 receptor) \\
ITGA6 & 3655 & ITGA6 & Integrin $\alpha 6$ \\
CD1C & 911 & CD1C & CD1c molecule \\
ITGB3 & 3690 & ITGB3 & Integrin $\beta 3$ (platelet glycoprotein IIIa, antigen CD61) \\
CSF2 & 1437 & CSF2 & Colony stimulating factor 2 (granulocyte-macrophage) \\
CD1D & 912 & CD1D & CD1d molecule \\
CD34 & 947 & CD34 & CD34 molecule \\
FLT3 & 2322 & FLT3 & Fms-related tyrosine kinase 3 \\
KIT & 3815 & KIT & V-kit Hardy-Zuckerman 4 feline sarcoma viral oncogene homolog \\
TFRC & 7037 & TFRC & Transferrin receptor (p90, CD71) \\
CSF1R & 1436 & CSF1R & Colony stimulating factor 1 receptor \\
CSF3R & 1441 & CSF3R & Colony stimulating factor 3 receptor (granulocyte) \\
KEGG & & O1100 &
\end{tabular}

KEGG pathway - metabolic pathways - 01100

$\mathrm{C}=1104 ; \mathrm{O}=36 ; \mathrm{E}=14.22 ; \mathrm{R}=2.53$; rawP=4.90e-07; adjP=6.80e-06

\begin{tabular}{|c|c|c|c|}
\hline NDUFS1 & 4719 & NDUFS1 & NADH dehydrogenase (ubiquinone) Fe-S protein $1,75 \mathrm{kDa}$ (NADH-coenzyme $\mathrm{Q}$ reductase) \\
\hline PRDX6 & 9588 & PRDX6 & Peroxiredoxin 6 \\
\hline DHCR24 & 1718 & DHCR24 & 24-Dehydrocholesterol reductase \\
\hline ETNK1 & 55500 & ETNK1 & Ethanolamine kinase 1 \\
\hline ASL & 435 & ASL & Argininosuccinate lyase \\
\hline APRT & 353 & APRT & Adenine phosphoribosyltransferase \\
\hline NDUFAB1 & 4706 & NDUFAB1 & NADH dehydrogenase (ubiquinone) $1 \alpha / \beta$ subcomplex, $1,8 \mathrm{kDa}$ \\
\hline INPP1 & 3628 & INPP1 & Inositol polyphosphate-1-phosphatase \\
\hline PMM2 & 5373 & PMM2 & Phosphomannomutase 2 \\
\hline GSS & 2937 & GSS & Glutathione synthetase \\
\hline ACSS2 & 55902 & ACSS2 & Acyl-CoA synthetase short-chain family member 2 \\
\hline SC4MOL & 6307 & SC4MOL & Sterol-C4-methyl oxidase-like \\
\hline NMNAT2 & 23057 & NMNAT2 & Nicotinamide nucleotide adenylyltransferase 2 \\
\hline HMGCL & 3155 & HMGCL & 3-Hydroxymethyl-3-methylglutaryl-Coenzyme A lyase \\
\hline APIP & 51074 & APIP & APAF1 interacting protein \\
\hline SYNJ2 & 8871 & SYNJ2 & Synaptojanin 2 \\
\hline ALDH18A1 & 5832 & ALDH18A1 & Aldehyde dehydrogenase 18 family, member A1 \\
\hline GATM & 2628 & GATM & Glycine amidinotransferase (L-arginine:glycine amidinotransferase) \\
\hline PIK3C3 & 5289 & PIK3C3 & Phosphoinositide-3-kinase, class 3 \\
\hline FBP2 & 8789 & FBP2 & Fructose-1,6-bisphosphatase 2 \\
\hline ECHS1 & 1892 & ECHS1 & Enoyl Coenzyme A hydratase, short chain, 1, mitochondrial \\
\hline AK3L1 & 205 & AK3L1 & Adenylate kinase 3-like 1 \\
\hline HYI & 81888 & HYI & Hydroxypyruvate isomerase homolog (E. coli) \\
\hline BST1 & 683 & BST1 & Bone marrow stromal cell antigen 1 \\
\hline H6PD & 9563 & H6PD & Hexose-6-phosphate dehydrogenase (glucose 1-dehydrogenase) \\
\hline ATP5F1 & 515 & ATP5F1 & ATP synthase, $\mathrm{H}^{+}$transporting, mitochondrial $\mathrm{F} 0$ complex, subunit $\mathrm{B} 1$ \\
\hline ADSS & 159 & ADSS & Adenylosuccinate synthase \\
\hline MGAT2 & 4247 & MGAT2 & Mannosyl ( $\alpha$-1,6-)-glycoprotein $\beta$-1,2-N-acetylglucosaminyltransferase \\
\hline NT5C2 & 22978 & NT5C2 & 5'-nucleotidase, cytosolic II \\
\hline EPRS & 2058 & EPRS & Glutamyl-prolyl-tRNA synthetase \\
\hline PGK1 & 5230 & PGK1 & Phosphoglycerate kinase 1 \\
\hline G6PD & 2539 & G6PD & Glucose-6-phosphate dehydrogenase \\
\hline MAOA & 4128 & MAOA & Monoamine oxidase A \\
\hline HK1 & 3098 & HK1 & Hexokinase 1 \\
\hline AMPD1 & 270 & AMPD1 & Adenosine monophosphate deaminase 1 (isoform $\mathrm{M}$ ) \\
\hline HAO1 & 54363 & HAO1 & Hydroxyacid oxidase (glycolate oxidase) 1 \\
\hline
\end{tabular}


Table IV. Continued.

KEGG pathway - JAK-STAT signaling pathway - 04630

$\mathrm{C}=155 ; \mathrm{O}=11 ; \mathrm{E}=2.00 ; \mathrm{R}=5.51 ;$ raw $\mathrm{P}=6.00 \mathrm{e}-06$; adj $\mathrm{P}=5.00 \mathrm{e}-05$

$\begin{array}{llll}\text { IFNG } & 3458 & \text { IFNG } & \text { Interferon } \gamma \\ \text { EP300 } & 2033 & \text { EP300 } & \text { E1 A binding protein p300 } \\ \text { IL7 } & 3574 & \text { IL7 } & \text { Interleukin } 7 \\ \text { IFNGR2 } & 3460 & \text { IFNGR2 } & \text { Interferon } \gamma \text { receptor } 2 \text { (interferon } \gamma \text { transducer 1) } \\ \text { STAT1 } & 6772 & \text { STAT1 } & \text { Signal transducer and activator of transcription 1, 91 kDa } \\ \text { CNTFR } & 1271 & \text { CNTFR } & \text { Ciliary neurotrophic factor receptor } \\ \text { IL9 } & 3578 & \text { IL9 } & \text { Interleukin } 9 \\ \text { CSF2 } & 1437 & \text { CSF2 } & \text { colony stimulating factor 2 (granulocyte-macrophage) } \\ \text { LIFR } & 3977 & \text { LIFR } & \text { Leukemia inhibitory factor receptor } \alpha \\ \text { IL12B } & 3593 & \text { IL12B } & \text { Interleukin } 12 B \text { (natural killer cell stimulatory factor 2, cytotoxic lymphocyte maturation factor 2, p40) } \\ \text { CSF3R } & 1441 & \text { CSF3R } & \text { Colony stimulating factor 3 receptor (granulocyte) }\end{array}$

KEGG pathway - cell cycle - 04110

$\mathrm{C}=128 ; \mathrm{O}=10 ; \mathrm{E}=1.65 ; \mathrm{R}=6.07 ;$ rawP=6.78e-06; adjP=5.02e- 05

$\begin{array}{llll}\text { EP300 } & 2033 & \text { EP300 } & \text { E1A binding protein p300 } \\ \text { CDKN2C } & 1031 & \text { CDKN2C } & \text { Cyclin-dependent kinase inhibitor 2C (p18, inhibits CDK4) } \\ \text { BUB3 } & 9184 & \text { BUB3 } & \text { Budding uninhibited by benzimidazoles 3 homolog (yeast) } \\ \text { TGFB3 } & 7043 & \text { TGFB3 } & \text { Transforming growth factor } \beta 3 \\ \text { ORC1L } & 4998 & \text { ORC1L } & \text { Origin recognition complex, subunit 1-like (yeast) } \\ \text { TGFB2 } & 7042 & \text { TGFB2 } & \text { Transforming growth factor } \beta 2 \\ \text { CDKN2D } & 1032 & \text { CDKN2D } & \text { Cyclin-dependent kinase inhibitor 2D (p19, inhibits CDK4) } \\ \text { CDC2 } & 983 & \text { CDC2 } & \text { Cell division cycle 2, G1 to S and G2 to M } \\ \text { MCM3 } & 4172 & \text { MCM3 } & \text { Minichromosome maintenance complex component 3 } \\ \text { RAD21 } & 5885 & \text { RAD21 } & \text { RAD21 homolog (S. pombe) }\end{array}$

KEGG pathway - MAPK signaling pathway - 04010

$\mathrm{C}=269 ; \mathrm{O}=14 ; \mathrm{E}=3.46 ; \mathrm{R}=4.04 ;$ rawP=1 $25 \mathrm{e}-05 ;$ adjP=8.67e-05

$\begin{array}{llll}\text { RPS6KA2 } & 6196 & \text { RPS6KA2 } & \text { Ribosomal protein S6 kinase, } 90 \mathrm{kDa} \text {, polypeptide } 2 \\ \text { STK3 } & 6788 & \text { STK3 } & \text { Serine/threonine kinase } 3 \text { (STE20 homolog, yeast) } \\ \text { MAPKAPK3 } & 7867 & \text { MAPKAPK3 } & \text { Mitogen-activated protein kinase-activated protein kinase } 3 \\ \text { RAPGEF2 } & 9693 & \text { RAPGEF2 } & \text { Rap guanine nucleotide exchange factor (GEF) } 2 \\ \text { CACNB2 } & 783 & \text { CACNB2 } & \text { Calcium channel, voltage-dependent } \beta 2 \text { subunit } \\ \text { TGFB3 } & 7043 & \text { TGFB3 } & \text { Transforming growth factor } \beta 3 \\ \text { PPP3CC } & 5533 & \text { PPP3CC } & \text { Protein phosphatase } 3 \text { (formerly 2B), catalytic subunit, } \gamma \text { isoform } \\ \text { MAPK13 } & 5603 & \text { MAPK13 } & \text { Mitogen-activated protein kinase 13 } \\ \text { TGFB2 } & 7042 & \text { TGFB2 } & \text { Transforming growth factor } \beta 2 \\ \text { MAPK10 } & 5602 & \text { MAPK10 } & \text { Mitogen-activated protein kinase } 10 \\ \text { FGF23 } & 8074 & \text { FGF23 } & \text { Fibroblast growth factor } 23 \\ \text { MAPK14 } & 1432 & \text { MAPK14 } & \text { Mitogen-activated protein kinase } 14 \\ \text { PDGFB } & 5155 & \text { PDGFB } & \text { Platelet-derived growth factor } \beta \text { polypeptide [simian sarcoma viral (v-sis) oncogene homolog] } \\ \text { RPS6KA3 } & 6197 & \text { RPS6KA3 } & \text { Ribosomal protein S6 kinase, } 90 \mathrm{kDa} \text {, polypeptide 3 }\end{array}$

KEGG pathway----Regulation of actin cytoskeleton----04810

$\mathrm{C}=216 ; \mathrm{O}=12 ; \mathrm{E}=2.78 ; \mathrm{R}=4.31 ; \mathrm{rawP}=2.73 \mathrm{e}-05 ; \mathrm{adj} \mathrm{P}=0.0002$

$\begin{array}{llll}\text { PDGFC } & 56034 & \text { PDGFC } & \text { platelet derived growth factor C } \\ \text { ARHGEF6 } & 9459 & \text { ARHGEF6 } & \text { Rac/Cdc42 guanine nucleotide exchange factor (GEF) } 6 \\ \text { ITGA4 } & 3676 & \text { ITGA4 } & \text { Integrin } \alpha 4 \text { (antigen CD49D, } \alpha \text { 4 subunit of VLA-4 receptor) } \\ \text { ARHGEF7 } & 8874 & \text { ARHGEF7 } & \text { Rho guanine nucleotide exchange factor (GEF) } 7 \\ \text { ITGA6 } & 3655 & \text { ITGA6 } & \text { Integrin } \alpha 6 \\ \text { ITGB3 } & 3690 & \text { ITGB3 } & \text { Integrin } \beta 3 \text { (platelet glycoprotein IIIa, antigen CD61) } \\ \text { PPP1CB } & 5500 & \text { PPP1CB } & \text { Protein phosphatase } 1 \text {, catalytic subunit } \beta \text { isoform } \\ \text { ITGB4 } & 3691 & \text { ITGB4 } & \text { Integrin } \beta 4 \\ \text { PDGFB } & 5155 & \text { PDGFB } & \text { Platelet-derived growth factor } \beta \text { polypeptide [simian sarcoma viral (v-sis) oncogene homolog] } \\ \text { TIAM1 } & 7074 & \text { TIAM1 } & \text { T-cell lymphoma invasion and metastasis } 1 \\ \text { FGF23 } & 8074 & \text { FGF23 } & \text { Fibroblast growth factor } 23 \\ \text { PIP4K2A } & 5305 & \text { PIP4K2A } & \text { Phosphatidylinositol-5-phosphate 4-kinase, type II } \alpha\end{array}$

KEGG pathway - proteasome - 03050

$\mathrm{C}=48 ; \mathrm{O}=4 ; \mathrm{E}=0.62 ; \mathrm{R}=6.47 ;$ rawP $=0.0034 ;$ adj $\mathrm{P}=0.0077$

$\begin{array}{llll}\text { IFNG } & 3458 & \text { IFNG } & \text { Interferon } \gamma \\ \text { POMP } & 51371 & \text { POMP } & \text { Proteasome maturation protein } \\ \text { PSMA2 } & 5683 & \text { PSMA2 } & \text { Proteasome (prosome, macropain) subunit } \alpha \text { type, } 2 \\ \text { PSME4 } & 23198 & \text { PSME4 } & \text { Proteasome (prosome, macropain) activator subunit } 4\end{array}$



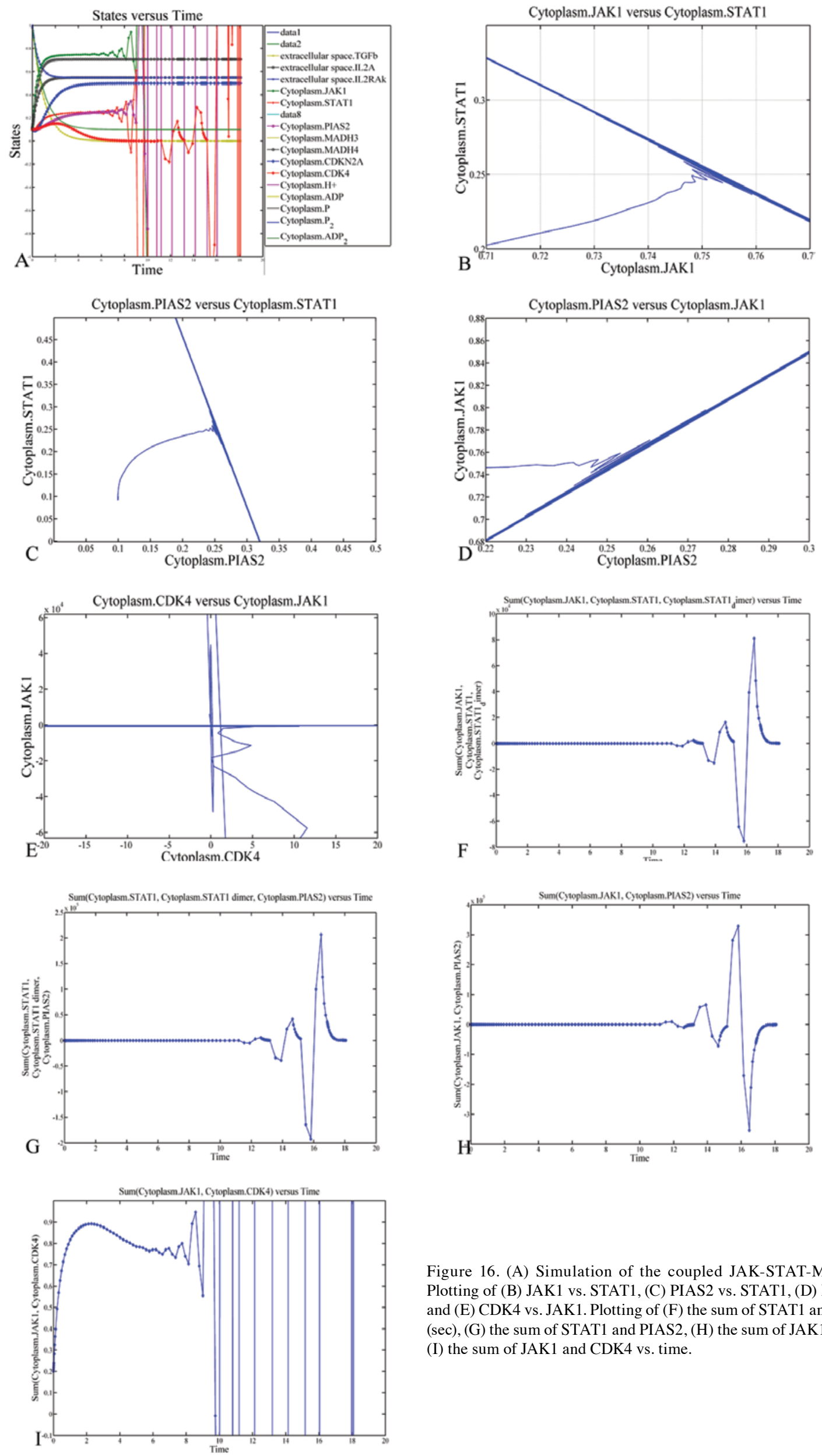

Figure 16. (A) Simulation of the coupled JAK-STAT-MAPK pathway Plotting of (B) JAK1 vs. STAT1, (C) PIAS2 vs. STAT1, (D) PIAS2 vs. JAK1 and (E) CDK4 vs. JAK1. Plotting of (F) the sum of STAT1 and JAK1 vs. time $(\mathrm{sec}),(\mathrm{G})$ the sum of STAT1 and PIAS2, (H) the sum of JAK1 and PIAS2 and (I) the sum of JAK1 and CDK4 vs. time. 
reported that both VEGF and PDGF families are involved in neo-angiogenesis in embryos and tumors (84). RMSs have been reported to express IGF and PDGF receptors (6). However, receptor expression is independent of signal molecule expression. The expression of PDGF has been associated with poor prognosis (6). MET is the receptor of the hepatocyte growth factor (produced by bone marrow stromal cells) (85) specific for the acute phase of T-ALL (86). It has also been reported to play a role in chronic myeloid leukemia (87) as well as to be expressed in B-ALL cells possessing the TEL-AML1 translocation, but not in B-ALL cells without this translocation (88). At the same time, FLT3 is known to cause AML when a mutation is present in this receptor (89). Members of the PDGF family of signaling molecules appear to be active in the two cell types studied. This suggests that both cell types utilize the same molecules for their signaling purposes. Since the PDGF family molecules are active in embryogenesis and hemopoietic cell differentiation, it can be assumed that in the present system, a developmental mechanism is still active after the occurrence of the malignancy.

ECM-receptor interactions. In this signaling pathway, the two cell types share two genes with equal expression: Thrombospondin-4 (THBS4) and integrin (ITGA6). ITGA6 is known to be expressed in childhood hematologic malignancies (90), whereas there are no reports linking THBS4 with leukemia or RMS. Both are signaling molecules, playing a role in ECM-receptor interaction.

Focal adhesion. Both the ECM-receptor and cytokine-receptor interaction signaling are interrelated to focal adhesion. Our system predicted two signal transduction pathways: The first includes the ECM-receptor signaling over LAMB2-ITGA6CAPN2-VASP-cell motility and the second includes cytokine induction over VEGF-MET/ACK1/-ELK1-cell proliferation. Elk1 was not found to be expressed by the microarray screening but it was correctly predicted from the TFBM analysis.

CAPN2 is a known regulator of cell migration of various cell types (91) but its role in either leukemia or RMS is not reported. Similarly, for LAMB2 there are no known reports of its relation to leukemia or RMS. In our system, these two molecules were predicted to play a role in migration for the two cell types studied. ACK1 is a known cell cycle regulator whose overexpression is related with cancer and EGFR downregulation $(92,93)$. Of note, in the present system ACK1 was equivalently expressed, while EGFR was overexpressed in the TE-671 cells. Elk-1, the predicted TF, appears to be involved in direct association with the focal adhesion kinase and MAP kinase, inducing anti-apoptosis (94). There is a direct connection between the focal adhesion pathway and cell cycle regulation through the MAPK pathway. Our system correctly predicted that the mediator for this transition is the Elk-1 TF, for both cell types.

$J A K-S T A T / M A P K$ signaling pathways. Signaling in the JAK-STAT pathway was predicted to start with the interleukins IL2, IL8, IL9 and their receptors, common for both cell types. The interleukin receptor binds to the JAK kinase which activates by phosphorylation (95) the STAT1 TF $(96,97)$. The STAT1 TF remains dormant in the cytoplasm until activated by JAK; then it translocates to the nucleus signaling the expression of genes responsible for proliferation, growth and differentiation. The STAT1 and STAT5B TFs appeared to be expressed in the present system, whereas STAT1 was also predicted by TFBM analysis. Both TFs were overexpressed in the TE-671 cells compared to CCRF-CEM. At the same time, both cell types express PIAS2 (PIASx $\alpha$ ) a known STAT1 inhibitor acting as a E3 ligase (95). When STAT1 translocates to the nucleus it interacts with histone acetyltransferase (CREB-binding protein) co-factor (98) and $\mathrm{NF}-\kappa \mathrm{B}$ to initiate transcription (99). This part of the JAK-STAT pathway can initiate gene transcription leading to proliferation, differentiation and development. On the other hand, there is the alternative regulation of cell proliferation by cytokines through the activation of the MAPK pathway via protein tyrosine phosphatases and the Ras/ MAPK pathway (100). The activation over the Ras/MAPK pathway involves signaling from cytokines such as PDGFA or PDGFB, both expressed in our system, the activation of HRAS and subsequent activation of RAF/MAPK/ERK also known to be involved in myeloid cell terminal differentiation (101). Following these events, a new protein of the serine/ threonine kinases (RPS6KA3) is involved which participates in the Ras/Raf/MAPK pathway (102). RPS6KA3 interacts with CREB TF, predicted by TFBM analysis, leading to gene regulation concerning cell proliferation. Alternative to this is the activation of the Elk-1 TF from ERK kinase. The Elk-1 TF is phosphorylated by the MAP kinases (103) and recruited by the SRF TF $(104,105)$. The SRF factor binds gene promoters that possess the serum response elements (SREs) in order to induce immediate early (IE) genes such as c-FOS and EGR-1 (106). Interestingly, the SRF TF was predicted by the TFBM analysis while the genes EGR-1, -2, -3, -4 and FOSB appeared to be expressed in our system. Alternatively, it has been reported that TGF- $\beta$ activates the MAPK signaling pathway via the $\mathrm{p} 38$ / MAPK pathway (107). Of note, TGF- $\beta$ and p38 were expressed in the two cell types under study, and were equally regulated, suggesting thus, a common utilization of this pathway for cell proliferation. In particular, TGF- $\beta$ activates members of the MAPK pathway such as c-JUN, which in turn activate the stress-activated kinase p38 (108-111). The p38 kinase is known to interact with Elk-1 and ATF-2 TFs (112-115). The ATF-2 TF was also predicted by the TFBM analysis.

The mechanisms described, appear to be common for both the leukemia and RMS cells studied. To our knowledge, a number of these mechanisms are known for leukemic cells; however, to date, there are no reports on sarcoma or RMS cells. Finally, another pathway that our analysis predicted involves the interaction of the p38 kinase with the MAX TF (MYC associated factor X) known to form complexes along with other proteins for gene regulation (116). In particular, the JAK-STAT pathway is essential for embryonic stem cell renewal and proliferation (117), suggesting that it is still active in the present system.

Cell cycle. Though we have described the signaling pathways that affect cell proliferation, we have not described how these are finally implemented in the cell cycle itself. A key regulator of cell cycle progression is the MAPK pathway. Depending on the signaling of MAPK, the cell cycle pathway receives signals in order to proceed or stop its progression. In our system, it seems that key-molecules of the MAPK pathway signal down- 
stream the activation of cell cycle progression. The cell cycle in these two cell types follows a time-dependent shift from the G1- to the S phase, while the G2-phase remains practically constant (Fig. 2C and D). The CCRF-CEM cell line has a defective TP53 gene (118) which appears to be unable to interact with PCNA. Also, PCNA expression is linked to the S-phase transition (119) which agrees with our result showing that PCNA is overexpressed in the leukemic cells which progress more rapidly into S-phase than the RMS cells. Interestingly, histone deacetylase 7 (HDAC7), expressed in our system, is a class II histone deacetylase, known to be tissue-specific (120). This class of histone deacetylases is an anti-apoptotic factor reported in thymocytes (121) overexpressed in the RMS cells.

Modelling JAK-STAT/MAPK and TGF- $\beta$ signaling pathways. In our search for oncogenic drivers, we attempted to model the JAK-STAT-MAPK-TGF- $\beta$ pathways. This analysis revealed that JAK1, STAT1, PIAS2 and CDK4 are possible gene candidates. The fact that these molecules thrive to infinitesimal oscillatory behavior, in the absence of inhibitory mechanisms, enables them to be candidate oncogenic drivers. A number of genes have already been reported as possible oncogenic drivers, such as the PRDM proteins, which belong to the SET domain family of histone methyltransferases. Enzymatic activity has been determined for only a few PRDMs suggesting that they act by recruiting co-factors or, more speculatively, confer methylation of non-histone targets. PRDM family members are deregulated in human diseases, especially in hematological malignancies and solid cancers, where they can act as both tumor suppressors and oncogenic drivers (122). Similar reports have shown the existence of such genes in glioblastoma, where a post-transcriptional regulation layer of surprising magnitude, comprising more than 248,000 microRNA-mediated interactions was revealed. Analyses in cell lines confirmed that this network regulates established drivers of tumor initiation and subtype implementation, including PTEN, PDGFRA, RB1, VEGFA, STAT3 and RUNX1, suggesting that these interactions mediate crosstalk between canonical oncogenic pathways (123). This is in agreement with our data, since we also predicted the possible role of VEGF, PDGF and STAT molecules in oncogenesis. It is also interesting that these molecules play a role in the diversity of the hematopoetic population and possibly in the leukemic populations (124). These observations bring mutations to mind. It was thought that mutations are the main driving force of tumors. However, based on the present predictions and a previous report on the so-called 'backseat drivers' (125), it is possible that mutations are not the leading or driving events in tumors. From the present predictions, it appears that there are certain molecules in a pathway that function in an unpredictable way, which can lead a system towards infinity. In other words, these molecules are capable of driving the progression of the cell cycle. Thus, a malfunction and not solely one mutation could thus be the leading event in tumorigenesis. To the best of our knowledge there are no reports referring to the non-linear nature of the gene behavior of JAK, STAT and PIAS2. However, it has been reported that the CDK family of proteins follow non-linear dynamics as potentiators of the cell cycle, and this is in agreement with our predictions. Further investigations on this topic would give us more insight on the mechanics of gene regulation and could possibly lead to the discovery of new prognostic or therapeutic targets.

In conclusion, the present study reveals a new holistic approach to understanding the dynamics of tumoral onset and possible driving forces. JAK1, STAT1, PIAS2 and CDK4 were predicted to be the driving forces in the CCRF-CEM and TE-671 cell lines. It is also suggested that mutations are not the sole driving forces behind tumorigenesis. Various neoplasms bearing different characteristics are expected to possess different traits and phenotypes. However, an approach to identify commonalities between such diverse biological systems, could possibly lead to the understanding of the common mechanisms that transform the physiological cells into malignant ones.

\section{Acknowledgements}

This study was supported in part by an independent research grant from the Financial Mechanism Office of Iceland, Liechtenstein and Norway and the Hellenic Ministry of Economy, Competitiveness and Shipping to Professor G.P. Chrousos.

\section{References}

1. Nicolis SK: Cancer stem cells and 'stemness' genes in neurooncology. Neurobiol Dis 25: 217-229, 2007.

2. Perilongo G, Felix CA, Meadows AT, Nowell P, Biegel J and Lange BJ: Sequential development of Wilms tumor, T-cell acute lymphoblastic leukemia, medulloblastoma and myeloid leukemia in a child with type 1 neurofibromatosis: a clinical and cytogenetic case report. Leukemia 7: 912-915, 1993.

3. Jacobs JF, Brasseur F, Hulsbergen-van de Kaa CA, et al: Cancer-germline gene expression in pediatric solid tumors using quantitative real-time PCR. Int J Cancer 120: 67-74, 2007.

4. Jacobs JF, Grauer OM, Brasseur F, et al: Selective cancer-germline gene expression in pediatric brain tumors. J Neurooncol 88: 273-280, 2008.

5. Mhawech-Fauceglia P, Herrmann FR, Bshara W, et al: Friend leukaemia integration-1 expression in malignant and benign tumours: a multiple tumour tissue microarray analysis using polyclonal antibody. J Clin Pathol 60: 694-700, 2007.

6. Blandford MC, Barr FG, Lynch JC, Randall RL, Qualman SJ and Keller C: Rhabdomyosarcomas utilize developmental, myogenic growth factors for disease advantage: a report from the Children's Oncology Group. Pediatr Blood Cancer 46: 329-338, 2006.

7. Chang LW, Nagarajan R, Magee JA, Milbrandt J and Stormo GD: A systematic model to predict transcriptional regulatory mechanisms based on overrepresentation of transcription factor binding profiles. Genome Res 16: 405-413, 2006.

8. Pleasance ED, Stephens PJ, O'Meara S, et al: A small-cell lung cancer genome with complex signatures of tobacco exposure. Nature 463: 184-190, 2009.

9. Wood LD, Parsons DW, Jones S, et al: The genomic landscapes of human breast and colorectal cancers. Science 318: 1108-1113, 2007.

10. Mosse YP, Laudenslager M, Longo L, et al: Identification of ALK as a major familial neuroblastoma predisposition gene. Nature 455: 930-935, 2008.

11. Mardis ER, Ding L, Dooling DJ, et al: Recurring mutations found by sequencing an acute myeloid leukemia genome. N Engl J Med 361: 1058-1066, 2009.

12. Jones S, Zhang X, Parsons DW, et al: Core signaling pathways in human pancreatic cancers revealed by global genomic analyses. Science 321: 1801-1806, 2008.

13. Parsons DW JS, Zhang X, et al: An integrated genomic analysis of human glioblastoma multiforme. Science 26: 1807-1812, 2008.

14. Sandberg AA, Stone JF, Czarnecki L and Cohen JD: Hematologic masquerade of rhabdomyosarcoma. Am J Hematol 68: 51-57, 2001.

15. Parham DM, Pinto A, Tallini G and Novak RW: Rhabdomyosarcoma mimicking acute leukemia. Arch Pathol Lab Med 122: 1047,1998 
16. Morandi S, Manna A, Sabattini E and Porcellini A: Rhabdomyosarcoma presenting as acute leukemia. J Pediatr Hematol Oncol 18: 305-307, 1996.

17. Putti MC, Montaldi A, D'Emilio A, et al: Unusual leukemic presentation of rhabdomyosarcoma: report of two cases with immunological, ultrastructural and cytogenetical studies. Haematologica 76: 368-374, 1991.

18. Kaplinsky C, Frisch A, Cohen IJ, et al: T-cell acute lymphoblastic leukemia following therapy of rhabdomyosarcoma. Med Pediatr Oncol 20: 229-231, 1992.

19. Dedrick RL and Morrison PF: Carcinogenic potency of alkylating agents in rodents and humans. Cancer Res 52: 2464-2467, 1992.

20. Park DJ and Koeffler HP: Therapy-related myelodysplastic syndromes. Semin Hematol 33: 256-273, 1996.

21. Kelly PN, Dakic A, Adams JM, Nutt SL and Strasser A: Tumor growth need not be driven by rare cancer stem cells. Science 317 : 337, 2007.

22. Khan J, Simon R, Bittner M, et al: Gene expression profiling of alveolar rhabdomyosarcoma with cDNA microarrays. Cancer Res 58: 5009-5013, 1998

23. Miranda L, Wolf J, Pichuantes S, Duke R and Franzusoff A: Isolation of the human PC6 gene encoding the putative host protease for HIV-1 gp160 processing in $\mathrm{CD}^{+} \mathrm{T}$ lymphocytes Proc Natl Acad Sci USA 93: 7695-7700, 1996.

24. Naujokat C, Sezer O, Zinke H, Leclere A, Hauptmann S and Possinger K: Proteasome inhibitors induced caspase-dependent apoptosis and accumulation of p21WAF1/Cip1 in human immature leukemic cells. Eur J Haematol 65: 221-236, 2000.

25. Foley GE, Lazarus H, Farber S, Uzman BG, Boone BA and McCarthy RE: Continuous culture of human lymphoblasts from peripheral blood of a child with acute leukemia. Cancer 18 522-529, 1965

26. Uzman BG, Foley GE, Farber S and Lazarus H: Morphologic variations in human leukemic lymphoblasts (CCRF-CEM cells) after long-term culture and exposure to chemotherapeutic agents. A study with the electron microscope. Cancer 19: 1725-1742, 1966.

27. Sandstrom PA and Buttke TM: Autocrine production of extracellular catalase prevents apoptosis of the human CEM T-cell line in serum-free medium. Proc Natl Acad Sci USA 90: 4708-4712, 1993.

28. McAllister RM, Isaacs H, Rongey R, et al: Establishment of a human medulloblastoma cell line. Int J Cancer 20: 206-212, 1977.

29. Friedman HS, Bigner SH, McComb RD, et al: A model for human medulloblastoma. Growth, morphology, and chromosomal analysis in vitro and in athymic mice. J Neuropathol Exp Neurol 42: 485-503, 1983

30. McAllister RM, Melnyk J, Finkelstein JZ, Adams EC Jr and Gardner MB: Cultivation in vitro of cells derived from a human rhabdomyosarcoma. Cancer 24: 520-526, 1969.

31. Yeung CM, An BS, Cheng CK, Chow BK and Leung PC: Expression and transcriptional regulation of the $\mathrm{GnRH}$ receptor gene in human neuronal cells. Mol Hum Reprod 11: 837-842, 2005 .

32. Chu ES, Wong TK and Yow CM: Photodynamic effect in medulloblastoma: downregulation of matrix metalloproteinases and human telomerase reverse transcriptase expressions. Photochem Photobiol Sci 7: 76-83, 2008.

33. Ormerod MG and Payne AW: Display of three-parametric data acquired by a flow cytometer. Cytometry 8: 240-243, 1987.

34. Ormerod MG, Payne AW and Watson JV: Improved program for the analysis of DNA histograms. Cytometry 8: 637-641, 1987.

35. Watson JV, Chambers SH and Smith PJ: A pragmatic approach to the analysis of DNA histograms with a definable G1 peak Cytometry 8: 1-8, 1987.

36. Chung HW, Park SW, Chung JB, et al: Differences in genetic expression profiles between young-age and old-age gastric adenocarcinoma using cDNA microarray for endocrine disruptor study. Oncol Rep 12: 33-39, 2004.

37. Chatziioannou A, Moulos P and Kolisis FN: Gene ARMADA: an integrated multi-analysis platform for microarray data implemented in MATLAB. BMC Bioinformatics 10: 354, 2009.

38. Sifakis EG, Prentza A, Koutsouris D and Chatziioannou AA: Evaluating the effect of various background correction methods regarding noise reduction, in two-channel microarray data. Comput Biol Med: Nov 8, 2011 (Epub ahead of print).

39. Zhang D, Zhang M and Wells MT: Multiplicative background correction for spotted microarrays to improve reproducibility. Genet Res 87: 195-206, 2006.
40. Tseng GC, Oh MK, Rohlin L, Liao JC and Wong WH: Issues in cDNA microarray analysis: quality filtering, channel normalization, models of variations and assessment of gene effects. Nucleic Acids Res 29: 2549-2557, 2001.

41. Hoffmann R, Seidl T and Dugas M: Profound effect of normalization on detection of differentially expressed genes in oligonucleotide microarray data analysis. Genome Biol 3: RESEARCH0033, 2002.

42. Hoffmann R, Seidl T, Bruno L and Dugas M: Developmental markers of $B$ cells are superior to those of $T$ cells for identification of stages with distinct gene expression profiles. J Leukoc Biol 74: 602-610, 2003.

43. Yang IV, Chen E, Hasseman JP, et al: Within the fold: assessing differential expression measures and reproducibility in microarray assays. Genome Biol 3: research0062, 2002.

44. Shabalin AA, Tjelmeland H, Fan C, Perou CM and Nobel AB: Merging two gene-expression studies via cross-platform normalization. Bioinformatics 24: 1154-1160, 2008.

45. Ramasamy A, Mondry A, Holmes CC and Altman DG: Key issues in conducting a meta-analysis of gene expression microarray datasets. PLoS Med 5: e184, 2008.

46. Russel S, Meadows L and Russel RR: Microarray Technology in Practice. Elsevier Inc., London, 2009.

47. Benson DA, Karsch-Mizrachi I, Lipman DJ, Ostell J and Wheeler DL: GenBank. Nucleic Acids Res 31: 23-27, 2003.

48. Benson DA, Karsch-Mizrachi I, Lipman DJ, Ostell J and Wheeler DL: GenBank: update. Nucleic Acids Res 32: D23-D26, 2004.

49. Schuler GD: Sequence mapping by electronic PCR. Genome Res 7: 541-550, 1997.

50. Wheeler DL, Church DM, Edgar R, et al: Database resources of the National Center for Biotechnology Information: update. Nucleic Acids Res 32: D35-40, 2004.

51. Wheeler DL, Church DM, Federhen S, et al: Database resources of the National Center for Biotechnology. Nucleic Acids Res 31: 28-33, 2003.

52. Diehn M, Sherlock G, Binkley G, et al: SOURCE: a unified genomic resource of functional annotations, ontologies, and gene expression data. Nucleic Acids Res 31: 219-223, 2003.

53. Perez-Iratxeta C, Wjst M, Bork P and Andrade MA: G2D: a tool for mining genes associated with disease. BMC Genet 6: 45, 2005.

54. Causton H, Quackenbush J and Brazma A: Microarray gene expression data analysis : A beginner's guide. Blackwell Publishing, Malden, MA, 2003.

55. Cleveland W: Robust locally weighted regression and smoothing scatterplots. Journal of the American Statistical Association 74: 829-836, 1979.

56. Klipper-Aurbach Y, Wasserman M, Braunspiegel-Weintrob N, et al: Mathematical formulae for the prediction of the residual beta cell function during the first two years of disease in children and adolescents with insulin-dependent diabetes mellitus. Med Hypotheses 45: 486-490, 1995.

57. Storey JD and Tibshirani R: Statistical significance for genomewide studies. Proc Natl Acad Sci USA 100: 9440-9445, 2003.

58. Storey JD and Tibshirani R: Statistical methods for identifying differentially expressed genes in DNA microarrays. Methods Mol Biol 224: 149-157, 2003.

59. Cohen BA, Mitra RD, Hughes JD and Church GM: A computational analysis of whole-genome expression data reveals chromosomal domains of gene expression. Nat Genet 26: 183-186, 2000

60. Sturn A, Quackenbush J and Trajanoski Z: Genesis: cluster analysis of microarray data. Bioinformatics 18: 207-208, 2002.

61. Reyal F, Stransky N, Bernard-Pierrot I, et al: Visualizing chromosomes as transcriptome correlation maps: evidence of chromosomal domains containing co-expressed genes - a study of 130 invasive ductal breast carcinomas. Cancer Res 65: 1376-1383, 2005.

62. Zhang B, Schmoyer D, Kirov S and Snoddy J: GOTree Machine (GOTM): a web-based platform for interpreting sets of interesting genes using Gene Ontology hierarchies. BMC Bioinformatics 5: 16, 2004.

63. Cole SW, Yan W, Galic Z, Arevalo J and Zack JA: Expressionbased monitoring of transcription factor activity: the TELiS database. Bioinformatics 21: 803-810, 2005.

64. Wingender E, Dietze P, Karas H and Knuppel R: TRANSFAC: a database on transcription factors and their DNA binding sites. Nucleic Acids Res 24: 238-241, 1996.

65. Beisvag V, Junge FK, Bergum H, et al: GeneTools - application for functional annotation and statistical hypothesis testing. BMC Bioinformatics 7: 470, 2006. 
66. Rubinstein R and Simon I: MILANO - custom annotation of microarray results using automatic literature searches. BMC Bioinformatics 6: 12, 2005

67. Mlecnik B, Scheideler M, Hackl H, Hartler J, Sanchez-Cabo F and Trajanoski Z: PathwayExplorer: web service for visualizing high-throughput expression data on biological pathways. Nucleic Acids Res 33: W633-W637, 2005.

68. Kanehisa M: A database for post-genome analysis. Trends Genet 13: 375-376, 1997.

69. Nakao M, Bono H, Kawashima S, et al: Genome-scale Gene Expression Analysis and Pathway Reconstruction in KEGG Genome Inform Ser Workshop Genome Inform 10: 94-103, 1999.

70. Kanehisa M and Goto S: KEGG: kyoto encyclopedia of genes and genomes. Nucleic Acids Res 28: 27-30, 2000.

71. Kanehisa M: The KEGG database. Novartis Found Symp 247: 91-101; discussion 101-103, 119-128, 244-252, 2002.

72. Ogata H, Goto S, Sato K, Fujibuchi W, Bono H and Kanehisa M: KEGG: Kyoto Encyclopedia of Genes and Genomes. Nucleic Acids Res 27: 29-34, 1999.

73. Funahashi A, Morohashi M, Kitano $\mathrm{H}$ and Tanimura $\mathrm{N}$ : CellDesigner: a process diagram editor for gene-regulatory and biochemical networks. BioSilico 1: 159-162, 2003.

74. Funahashi A, Matsuoka Y, Jouraku A, Morohashi M, Kikuchi N and Kitano H: CellDesigner 3.5: A Versatile Modeling Tool for Biochemical Networks. Proceedings of the IEEE 96: 1254-1265, 2008.

75. Moutselos K, Kanaris I, Chatziioannou A, Maglogiannis I and Kolisis FN: KEGGconverter: a tool for the in-silico modelling of metabolic networks of the KEGG Pathways database. BMC Bioinformatics 10: 324, 2009.

76. Brown VI, Hulitt J, Fish J, et al: Thymic stromal-derived lymphopoietin induces proliferation of pre-B leukemia and antagonizes mTOR inhibitors, suggesting a role for interleukin-7Ralpha signaling. Cancer Res 67: 9963-9970, 2007.

77. Barata JT, Keenan TD, Silva A, Nadler LM, Boussiotis VA and Cardoso AA: Common gamma chain-signaling cytokines promote proliferation of T-cell acute lymphoblastic leukemia. Haematologica 89: 1459-1467, 2004.

78. Kiss C, Benko I and Kovacs P: Leukemic cells and the cytokine patchwork. Pediatr Blood Cancer 42: 113-121, 2004

79. Hiroi $\mathrm{M}$ and Ohmori Y: Constitutive nuclear factor kappaB activity is required to elicit interferon-gamma-induced expression of chemokine CXC ligand 9 (CXCL9) and CXCL10 in human tumour cell lines. Biochem J 376: 393-402, 2003.

80. de la Iglesia N, Konopka G, Puram SV, et al: Identification of a PTEN-regulated STAT3 brain tumor suppressor pathway. Genes Dev 22: 449-462, 2008

81. Yoshino J, Monkawa T, Tsuji M, Hayashi M and Saruta T: Leukemia inhibitory factor is involved in tubular regeneration after experimental acute renal failure. J Am Soc Nephrol 14: 3090-3101, 2003.

82. Niini T, Vettenranta K, Hollmen J, et al: Expression of myeloidspecific genes in childhood acute lymphoblastic leukemia - a cDNA array study. Leukemia 16: 2213-2221, 2002.

83. Ho CL, Hsu LF, Phyliky RL and Li CY: Autocrine expression of platelet-derived growth factor B in B cell chronic lymphocytic leukemia. Acta Haematol 114: 133-140, 2005

84. Karamysheva AF: Mechanisms of angiogenesis. Biochemistry (Mosc) 73: 751-762, 2008

85. Weimar IS, Miranda N, Muller EJ, et al: Hepatocyte growth factor/scatter factor $(\mathrm{HGF} / \mathrm{SF})$ is produced by human bone marrow stromal cells and promotes proliferation, adhesion and survival of human hematopoietic progenitor cells $\left(\mathrm{CD} 34^{+}\right)$. Exp Hematol 26: 885-894, 1998.

86. Choi YL, Tsukasaki K, O'Neill MC, et al: A genomic analysis of adult T-cell leukemia. Oncogene 26: 1245-1255, 2007.

87. Zhelyazkova AG, Tonchev AB, Kolova P, Ivanova L and Gercheva L: Prognostic significance of hepatocyte growth factor and microvessel bone marrow density in patients with chronic myeloid leukaemia. Scand J Clin Lab Invest 1-9, 2008.

88. Accordi B, Pillozzi S, Dell'Orto MC, et al: Hepatocyte growth factor receptor c-MET is associated with FAS and when activated enhances drug-induced apoptosis in pediatric B acute lymphoblastic leukemia with TEL-AML1 translocation. J Biol Chem 282: 29384-29393, 2007.

89. Scholl C, Gilliland DG and Frohling S: Deregulation of signaling pathways in acute myeloid leukemia. Semin Oncol 35: 336-345, 2008.

90. Hara J, Matsuda Y, Fujisaki H, et al: Expression of adhesion molecules in childhood B-lineage-cell neoplasms. Int J Hematol 72: 69-73, 2000
91. Raynaud F, Marcilhac A, Chebli K, Benyamin Y and Rossel M: Calpain 2 expression pattern and sub-cellular localization during mouse embryogenesis. Int J Dev Biol 52: 383-388, 2008.

92. Grovdal LM, Johannessen LE, Rodland MS, Madshus IH and Stang E: Dysregulation of Ack1 inhibits down-regulation of the EGF receptor. Exp Cell Res 314: 1292-1300, 2008.

93. Shen F, Lin Q, Gu Y, Childress C and Yang W: Activated Cdc42associated kinase 1 is a component of EGF receptor signaling complex and regulates EGF receptor degradation. Mol Biol Cell 18: 732-742, 2007.

94. Mamali I, Kotsantis P, Lampropoulou M and Marmaras VJ: Elk-1 associates with FAK, regulates the expression of FAK and MAP kinases as well as apoptosis in HK-2 cells. J Cell Physiol 216: 198-206, 2008.

95. Rogers RS, Horvath CM and Matunis MJ: SUMO modification of STAT1 and its role in PIAS-mediated inhibition of gene activation. J Biol Chem 278: 30091-30097, 2003.

96. Kisseleva T, Bhattacharya S, Braunstein J and Schindler CW: Signaling through the JAK/STAT pathway, recent advances and future challenges. Gene 285: 1-24, 2002.

97. Levy DE and Darnell JE Jr: Stats: transcriptional control and biological impact. Nat Rev Mol Cell Biol 3: 651-662, 2002.

98. Korzus E, Torchia J, Rose DW, et al: Transcription factorspecific requirements for coactivators and their acetyltransferase functions. Science 279: 703-707, 1998.

99. Hiroi $\mathrm{M}$ and Ohmori Y: The transcriptional coactivator CREBbinding protein cooperates with STAT1 and NF-kappa B for synergistic transcriptional activation of the CXC ligand 9/ monokine induced by interferon-gamma gene. J Biol Chem 278: 651-660, 2003.

100. So EY, Oh J, Jang JY, Kim JH and Lee CE: Ras/Erk pathway positively regulates Jak1/STAT6 activity and IL-4 gene expression in Jurkat T cells. Mol Immunol 44: 3416-3426, 2007.

101. Dorsey JF, Cunnick JM, Mane SM and Wu J: Regulation of the Erk2-Elk1 signaling pathway and megakaryocytic differentiation of Bcr-Abl(+) K562 leukemic cells by Gab2. Blood 99: 1388-1397, 2002.

102. Delaunoy J, Abidi F, Zeniou M, et al: Mutations in the X-linked RSK2 gene (RPS6KA3) in patients with Coffin-Lowry syndrome. Hum Mutat 17: 103-116, 2001.

103. Yang SH, Shore P, Willingham N, Lakey JH and Sharrocks AD: The mechanism of phosphorylation-inducible activation of the ETS-domain transcription factor Elk-1. EMBO J 18: 5666-5674, 1999.

104. Sharrocks AD: The ETS-domain transcription factor family. Nat Rev Mol Cell Biol 2: 827-837, 2001.

105. Shaw PE and Saxton J: Ternary complex factors: prime nuclear targets for mitogen-activated protein kinases. Int J Biochem Cell Biol 35: 1210-1226, 2003.

106.Zhang HM, Li L, Papadopoulou N, et al: Mitogen-induced recruitment of ERK and MSK to SRE promoter complexes by ternary complex factor Elk-1. Nucleic Acids Res 36: 2594-2607, 2008.

107. Ohshima T and Shimotohno K: Transforming growth factor-betamediated signaling via the p38 MAP kinase pathway activates Smad-dependent transcription through SUMO-1 modification of Smad4. J Biol Chem 278: 50833-50842, 2003.

108. Hu PP, Shen X, Huang D, Liu Y, Counter C and Wang XF: The MEK pathway is required for stimulation of $\mathrm{p} 21$ (WAF1/CIP1) by transforming growth factor-beta. J Biol Chem 274: 35381-35387, 1999.

109. Yue J and Mulder KM: Requirement of Ras/MAPK pathway activation by transforming growth factor beta for transforming growth factor beta 1 production in a smad-dependent pathway. J Biol Chem 275: 35656, 2000.

110. Engel ME, McDonnell MA, Law BK and Moses HL: Interdependent SMAD and JNK signaling in transforming growth factor-beta-mediated transcription. J Biol Chem 274: 37413-37420, 1999.

111. Hocevar BA, Brown TL and Howe PH: TGF-beta induces fibronectin synthesis through a c-Jun N-terminal kinase-dependent, Smad4-independent pathway. EMBO J 18: 1345-1356, 1999.

112. Raingeaud J, Gupta S, Rogers JS, et al: Pro-inflammatory cytokines and environmental stress cause p38 mitogen-activated protein kinase activation by dual phosphorylation on tyrosine and threonine. J Biol Chem 270: 7420-7426, 1995.

113. Raingeaud J, Whitmarsh AJ, Barrett T, Derijard B and Davis RJ: MKK3- and MKK6-regulated gene expression is mediated by the p38 mitogen-activated protein kinase signal transduction pathway. Mol Cell Biol 16: 1247-1255, 1996. 
114. Whitmarsh AJ, Yang SH, Su MS, Sharrocks AD and Davis RJ: Role of p38 and JNK mitogen-activated protein kinases in the activation of ternary complex factors. Mol Cell Biol 17: 2360-2371, 1997.

115. Price MA, Cruzalegui FH and Treisman R: The $\mathrm{p} 38$ and ERK MAP kinase pathways cooperate to activate Ternary Complex Factors and c-fos transcription in response to UV light. EMBO J 15 : 6552-6563, 1996.

116. Lee CM, Onesime D, Reddy CD, Dhanasekaran N and Reddy EP: JLP: A scaffolding protein that tethers JNK/p38MAPK signaling modules and transcription factors. Proc Natl Acad Sci USA 99: 14189-14194, 2002.

117. Rho JY, Yu K, Han JS, et al: Transcriptional profiling of the developmentally important signalling pathways in human embryonic stem cells. Hum Reprod 21: 405-412, 2006.

118. Strasser-Wozak EM, Hartmann BL, Geley S, et al: Irradiation induces $\mathrm{G} 2 / \mathrm{M}$ cell cycle arrest and apoptosis in p53-deficient lymphoblastic leukemia cells without affecting Bcl-2 and Bax expression. Cell Death Differ 5: 687-693, 1998.
119. Tonkinson JL, Marder P, Andis SL, et al: Cell cycle effects of antifolate antimetabolites: implications for cytotoxicity and cytostasis. Cancer Chemother Pharmacol 39: 521-531, 1997.

120. Verdin E, Dequiedt F and Kasler HG: Class II histone deacetylases: versatile regulators. Trends Genet 19: 286-293, 2003.

121. Dequiedt F, Kasler H, Fischle W, et al: HDAC7, a thymus-specific class II histone deacetylase, regulates Nur77 transcription and TCR-mediated apoptosis. Immunity 18: 687-698, 2003.

122. Fog CK, Galli GG and Lund AH: PRDM proteins: Important players in differentiation and disease. Bioessays 34: 50-60, 2012

123. Sumazin P, Yang X, Chiu HS, et al: An extensive microRNAmediated network of RNA-RNA interactions regulates established oncogenic pathways in glioblastoma. Cell 147: 370-381, 2011.

124. Hoang T: The origin of hematopoietic cell type diversity. Oncogene 23: 7188-7198, 2004.

125. Futreal PA: Backseat drivers take the wheel. Cancer Cell 12: 493-494, 2007. 